\title{
HEDGE FUNDS: RISK AND PERFORMANCE
}

\author{
SANGHEON SHIN* \\ Department of Accounting 85 Finance \\ Percy J. Vaughn, Jr. College of Business Administration \\ Alabama State University, 915 S. Jackson St., Montgomery, AL 36117, USA \\ sangheonshin.fin@gmail.com \\ JAN SMOLARSKI \\ Department of Accounting and Finance \\ William G. Rohrer College of Business, Rowan University \\ 201 Mullica Road, Glassboro, NJ 08028, USA \\ GÖKÇE SOYDEMIR \\ Department of Accounting 8 Finance \\ College of Business Administration \\ California State University, Stanislaus \\ One University Circle, Turlock CA, 95382, USA
}

Accepted 2 May 2018

Published 12 June 2018

\begin{abstract}
This paper models hedge fund exposure to risk factors and examines time-varying performance of hedge funds. From existing models such as asset-based style (ABS)-factor model, standard asset class (SAC)-factor model, and four-factor model, we extract the best six factors for each hedge fund portfolio by investment strategy. Then, we find combinations of risk factors that explain most of the variance in performance of each hedge fund portfolio based on investment strategy. The results show instability of coefficients in the performance attribution regression. Incorporating a time-varying factor exposure feature would be the best way to measure hedge fund performance. Furthermore, the optimal models with fewer factors exhibit greater explanatory power than existing models. Using rolling regressions, our customized investment strategy model shows how hedge funds are sensitive to risk factors according to market conditions.
\end{abstract}

Keywords: Hedge funds; risk factor; performance; capital asset pricing model; instant history bias; survivorship bias.

JEL Codes: G11, G24

*Corresponding author.

This is an Open Access article published by World Scientific Publishing Company. It is distributed under the terms of the Creative Commons Attribution 4.0 (CC-BY) License. Further distribution of this work is permitted, provided the original work is properly cited. 


\section{Introduction}

It is well known that hedge funds are less regulated relative to traditional mutual funds enabling fund managers to take long/short positions in almost any financial instruments and use extremely high levels of leverage. Hedge fund managers are given almost full discretion in determining investment strategies, portfolio composition, and level of leverage. Highly skilled managers can actively respond to changes in market conditions and quickly adjust their portfolios and exposures to changes in various risk factors. Therefore, it is natural that such exposure is dynamic and time-varying.

Hedge funds adopt diverse investment strategies and provide investors with options to select hedge funds that best fit to their risk preference. Since hedge funds can go both long and short and/or can invest in most types of financial instruments, risk levels can vary from neutral to extremely high. Hedge fund managers usually announce risk characteristics or investment strategies of their funds to investors. Hedge funds likely exhibit different exposures to the changes in risk factors based on their investment strategies. For instance, fixed-income funds primarily invest in fixed-income securities, which are usually issued by corporations, banks, and governments. As the name implies, the interest payments are often fixed with respect to frequency and amount. As such, they are less exposed to equity market volatility and their performance tends to be stable and less sensitive to the equity market movements. However, equity hedge funds are highly exposed to changes in micro- and macro-economic conditions, as well as firm earnings and cash flow. Fung \& Hsieh (1997a) note that depending on investment strategies, hedge funds possibly achieve different levels of returns given the same or similar market environments. Therefore, it seems somewhat contradictory that a set of risk factors is used to estimate performance of hedge funds pursuing many different investment strategies, or that an aggregate hedge fund portfolio is used to represent those hedge funds by offsetting unique features of funds in each category.

Hedge fund investors are considered to be relatively well educated and knowledgeable in various aspects of investing suggesting that a significant part of any investment decision is based on analytics and underlying information. However, a sophisticated investor would still make a biased decision if the analysis is based on biased information or benchmarks. To be able to make unbiased performance analysis of hedge funds that use a variety of investment strategies, we need to develop a customized set of risk factor for each investment strategy. Our assertion is also related to a well-known fact that hedge funds actively respond to changes in market condition by adjusting their portfolio accordingly. This means that hedge funds can be very flexible as needed in adjusting their exposure to risk factors. However, traditional asset pricing models assume constant beta over the sample period. We therefore argue that constant-beta models do not work well since hedge funds actively and continuously respond to market conditions. Instead, asset pricing models need to be flexible so that they can catch and reflect responses to the changes in the market conditions.

The purpose of this study is therefore to develop the best customized models to optimally estimate hedge funds' dynamic performance and exposure with respect to 
investment strategies and sets of the corresponding risk factors. We make several attempts.

We first conduct clustering analysis based on the Pearson correlation-coefficients to group risk factors based on the standard asset class (SAC) factor model, assetbased style (ABS) model, and the four-factor model, neither of which consider any dynamic features of hedge funds. These models do select a few standard risk factors to explain hedge fund performance across the entire hedge fund universe rather than investment strategy specific factors. We do not expect that a risk factor can make equal contribution in explaining the performance of all hedge funds, which pursue different investment strategies. We also focus on the shortcomings that make the models less practical, on one hand, for investors looking for a certain type of fund that fits their risk preference or portfolio, and on the other hand, for fund managers determining risk preference of target investors. Our proposal leads necessarily to a narrow and focused model. In classifying hedge funds based on investment strategies, we can find a series of risk factors and models that may well capture hedge fund performance for each investment strategy. Among the four hedge fund investment strategies suggested by Agarwal et al. (2009), Relative Value (RV) relies on spread relationships to minimize exposure to risk factors. We expect that risk factors such as credit spread and the 10-year treasury yield as a proxy for bond-oriented risk factors can make a significant contribution compared to other investment strategies. Security Selection (SS) focuses on reducing systematic risk by taking long and short position in undervalued and overvalued assets. We expect that the Fama-French three-factor model can significantly contribute to explaining the performance of hedge funds following a SS strategy.

We then estimate single-factor rolling regression parameters using risk factors employed in existing models and find the top six factors for each hedge fund portfolio based on investment strategy. Analyzing recursive residuals from constant-beta models, we examine the stability of coefficients over time to show that constant-beta models do not properly measure dynamic exposure to risk factors, and that a rolling regression model is a better option to find the combinations of risk factors that explain most of the performance. Finally, we select an optimal model based on hedge fund investment strategy, which appropriately estimates dynamic performance and exposure to dynamic risk factors.

We find that there are two types of biases that bias hedge fund returns upwardly, and that these can be mitigated by handling the data appropriately. Our findings also reveal that the SAC-factor model is more likely to suffer from multicollinearity because risk factors are highly correlated with each other. We select one factor from each group of factors to eliminate this potential problem. By applying rolling regression analysis to the single-factor model, we show that risk factor coefficients are unstable across time. This can be attributed to the active and dynamic management of risk exposure responding to the changes in market conditions. We also statistically show that existing constant-beta models, which implicitly assume static or buy-and-hold investment strategies, cannot appropriately estimate hedge fund performance and 
exposure to risk factors. The proposed multi-factor rolling regression models based on investment strategy provide more explanatory power than the existing constant-beta models. Our models are also more parsimonious than the constant-beta models.

We contribute to the existing hedge fund literature in the following ways. First, we show that coefficients from our rolling regression analysis over time-varying windows are unstable. Thus, it is inappropriate to estimate hedge fund performance and exposure to risk factors with constant-beta models. Hedge fund managers can respond quickly to changes in market conditions. Therefore, employing rolling regression analysis would so far be the best way to reflect the dynamic features of hedge funds when measuring performance and exposures. Second, we find that the optimal models based on investment strategy best explain hedge fund performance and exposure to risk factors. The optimal models with fewer factors exhibit greater explanatory power than existing models, and rolling regression analysis makes the models more credible in estimating the active and dynamic management of hedge funds. In addition, by combining different factors tailored to investment strategies, we can make the models more elaborate and provide better insight into hedge fund management practices. The paired $t$-tests of $R$-squared statistics support our models showing significant improvements in explanatory power compared to ABS-, SAC- and Four-factor models.

The results for the Directional Trader (DT) strategy, which is based on predicting market price movements, show that $80 \%$ of the explanatory power lies within a model of two factors: emerging market return and volatility index (VIX). We conjecture that investment decisions of DT are highly based on equity market conditions. The results of RV and SS are within our expectations. As shown by the coefficient value and as expected, RV has a unique risk factor, credit spread. This appears to be the key risk factor in RV's investment decisions and can be attributed to investment style of RV, which is to maintain a certain level of return while minimizing risk. The return of SS is primarily explained by risk factors related with the equity market such as market risk premium, VIX and spread between returns of small and large companies. It is attributed to the feature of SS, which is to focus on reducing systematic risk. Using rolling regression analysis, we customize the investment strategy-specific model to clearly show how sensitive hedge fund risk factors are according to market conditions. The stability tests already show that rolling regression beta provides better fits to measure risk exposure of hedge funds actively responding to market conditions. A set of unique risk factors based on investment strategies surely helps to improve the models' explanatory power. With the optimal models developed in this study, we argue that investors are able to make better informed investment decisions based on their risk preferences.

\section{Data and Descriptive Statistics}

We use monthly time series returns for hedge funds, funds of hedge funds (FOFs), Fung \& Hsieh's ABS factor and SAC factor, Carhart (1997)'s four factors, a factor for DeBondt \& Thaler (1985)'s contrarian strategy, and a VIX. Returns for hedge 
funds and FoFs are collected from Global Hedge Fund Database provided by BarclayHedge. It provides data on 2689 (2072) active and 4200 (1845) inactive hedge funds. We exclude funds with observations for less than 12 months of observations; funds that report returns not in net-of-all fees; and funds that are not involved in the four broad investment strategies suggested by Agarwal et al. (2009). As a result, we have 2556 (1970) active and 3786 (1705) inactive hedge funds.

Existing research has repeatedly shown that because hedge fund data are voluntarily reported, data potentially suffer from survivorship and instant history (backfilled) biases. Fortunately, our database provides "graveyard" data, which include funds that have ceased reporting. By combining information for active and inactive funds, we can minimize the survivorship bias caused by liquidated or delisted hedge funds. Instant history bias (or backfilled bias) is caused by backfilledperiod information. We follow the general method of handling instant history bias by dropping returns of the first year.

Column (C) in Table 1 exhibits positive figures from about $0.24 \%$ to $2.3 \%$ on an annual basis across all investment strategies (significant at the $5 \%$ level). This indicates that hedge fund returns tend to be inflated by backfilled information, which can be at least partially eliminated by removing reported returns for the initial 12-month reporting. Column (D) shows positive figures for all investment strategies, but only three of six portfolios - AG, DT, and FoF - exhibit significant difference at $5 \%$ the level. In column (E), the difference between hedge fund portfolio returns that control for both and none of the biases all appear to be positive and significant, except in one case.

To control for biases, we remove returns of the first year since inception, and combine returns of active and inactive funds. The comparisons of these returns not only confirm the existence of instant history bias and survivorship bias, but also show that the ways we control for the biases appear to be quite effective.

We categorize hedge funds into four broad investment strategies following Agarwal et al. (2009) — DT, RV, SS, and multi-process (MP) — involving strategies provided by different vendors. We create six equally-weighted portfolios for aggregate hedge funds and FoFs, as well as for the four broad investment strategies. The data cover period from January 1994 to December 2008 (180 months). We select the sample period because since we have at least 40 hedge funds every month to make up each investment strategy portfolio. In addition, the majority of recent studies also choose sample period from 1994 to 2010 because (1) major database began providing information about funds that stop reporting, which controls for survivorship bias and (2) the time period in question includes several major events such as the dot.com bust and the mortgage financial crises. Recent studies (Aiken et al. 2015, Bali et al. 2014, Busiere et al. 2015, Qin \& Bai 2014); all of which use data sets ending in 2007 and 2009 and also focus on specific periods to study specific hedge fund phenomena. Following Fung \& Hsieh (2004a)'s ABS factor, we use the monthly total return of the S\&P 500 index as an "Equity market factor"; the monthly total return of Russell 2000 index less the S\&P 500 index as a "Size spread factor"; the monthly change in 


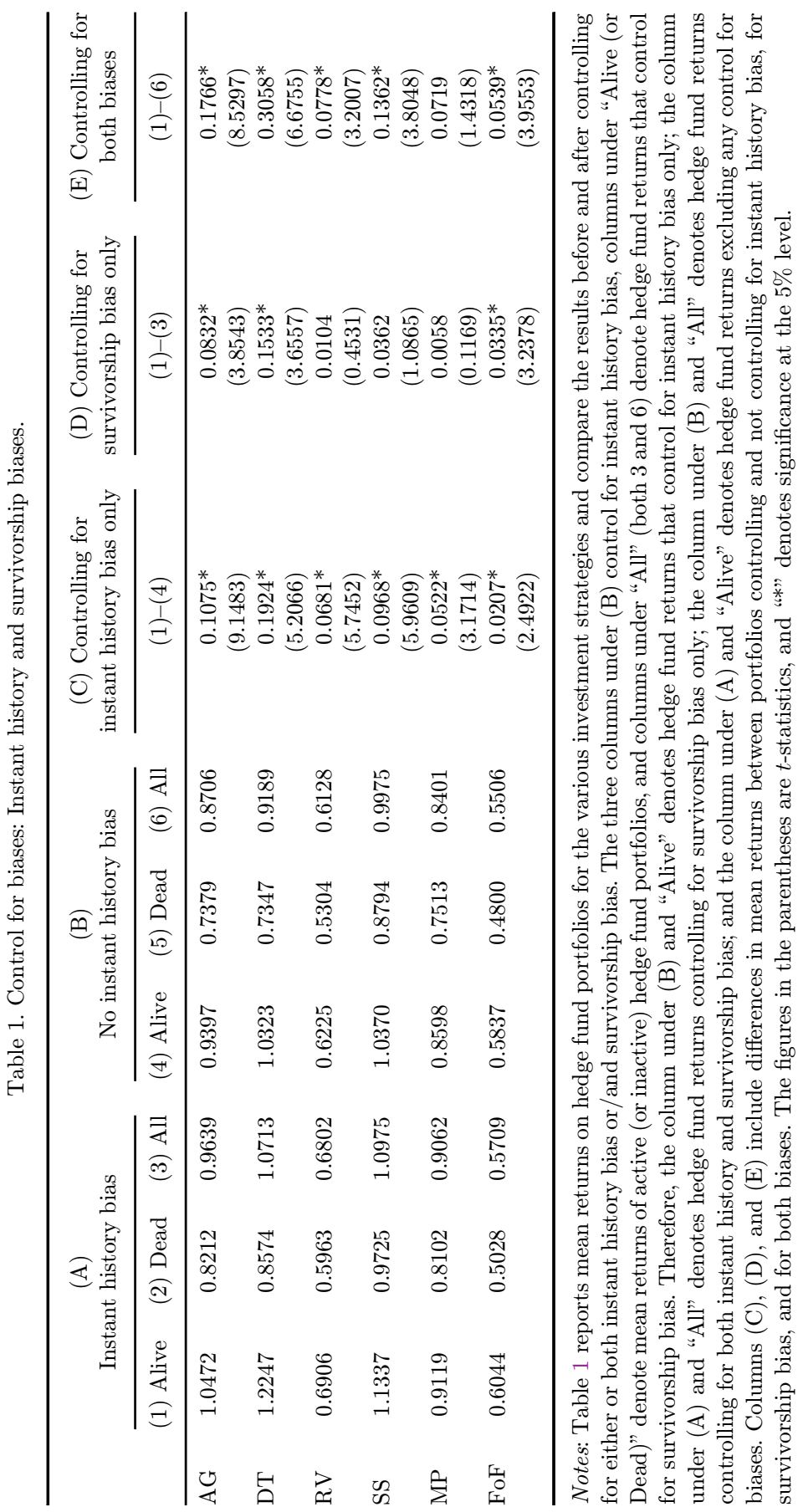


the 10-year constant maturity treasury yield as a "Bond market factor"; and the monthly change in Moody's Baa yield less 10-year treasury constant maturity yield as a "Credit spread factor." We also utilize SAC factor from Fung \& Hsieh (1997a): the MSCI North American equities as "US equities"; the MSCI non-US equities as "non-US equities"; the JPMorgan US Government bonds as "US Government bonds"; the JPMorgan non-US Government bonds as "Non-US Government bonds"; the one-month Eurodollar deposit rate of the previous month as the "Eurodollar deposit return"; the gold bullion in London bullion market as the "Spot Gold"; and the Federal Reserve Traded-Weighted Index of the US dollar against major currencies as the "US dollar index." The 10-year treasury constant maturity yield, Moody's Baa yield, and traded-weight index of the US dollar against major currencies are obtained from the Board of Governors of the Federal Reserve System. ${ }^{\text {a }}$ The remaining data were collected from DataStream. Carhart's four-factor model (the excess return on the market, the performance of small stocks relative to large stocks, the performance of value stocks relative to growth stocks, and momentum) and DeBondt and Thaler's Contrarian strategy are provided at the Professor French's home page. ${ }^{\mathrm{b}}$ In addition, we employ the Chicago Board Options Exchange Market VIX as a proxy for investor sentiment. The VIX is obtained from DataStream, and we use the value measured at the beginning of every month.

Panel A in Table 2 shows that the mean monthly returns on hedge fund portfolios ranged from $0.55 \%$ to $1.00 \%$ with standard deviations from $1.15 \%$ to $3.01 \%$. Among the four broad investment strategies, portfolios of DT and SS exhibit the highest mean monthly returns compared to two other portfolios of RV and MP while they also show the highest standard deviation. This is consistent with the idea that the higher the risk, the greater the return. In fact, the investments of DT and SS hedge funds are conducted based on market movement predictions or based on estimated asset values, leading to relatively greater risk. In contrast, RV hedge funds take positions by maintaining a certain level of spread to minimize risk or market exposure, leading to lower risk. FoFs show the lowest mean return and shape ratio. This can be partially attributed to the fact that investors pay fees to FoFs as well as hedge funds included in the portfolio of the FoFs.

Panel B in Table 2 reports that all risk factors, excluding Non-US Government Bonds and US Dollar Index, are non-normally distributed. Scott \& Horvath (1980) claim that investors with positive marginal utility are risk averse for all wealth levels and prefer higher first and third moments (mean and skewness) and lower second and fourth moments (standard deviation and kurtosis). By comparing descriptive statistics of hedge fund portfolios with those of equity market indexes (S\&P 500, US equity, non-US equity, emerging market, and market risk premium), hedge funds seem to be outperforming equity market indexes based only on mean and standard deviation. If we take skewness and kurtosis into account due to the non-normal

\footnotetext{
a http://www.federalreserve.gov/econresdata/releases/statisticsdata.htm.

b http://mba.tuck.dartmouth.edu/pages/faculty/ken.french/data_library.html.
} 


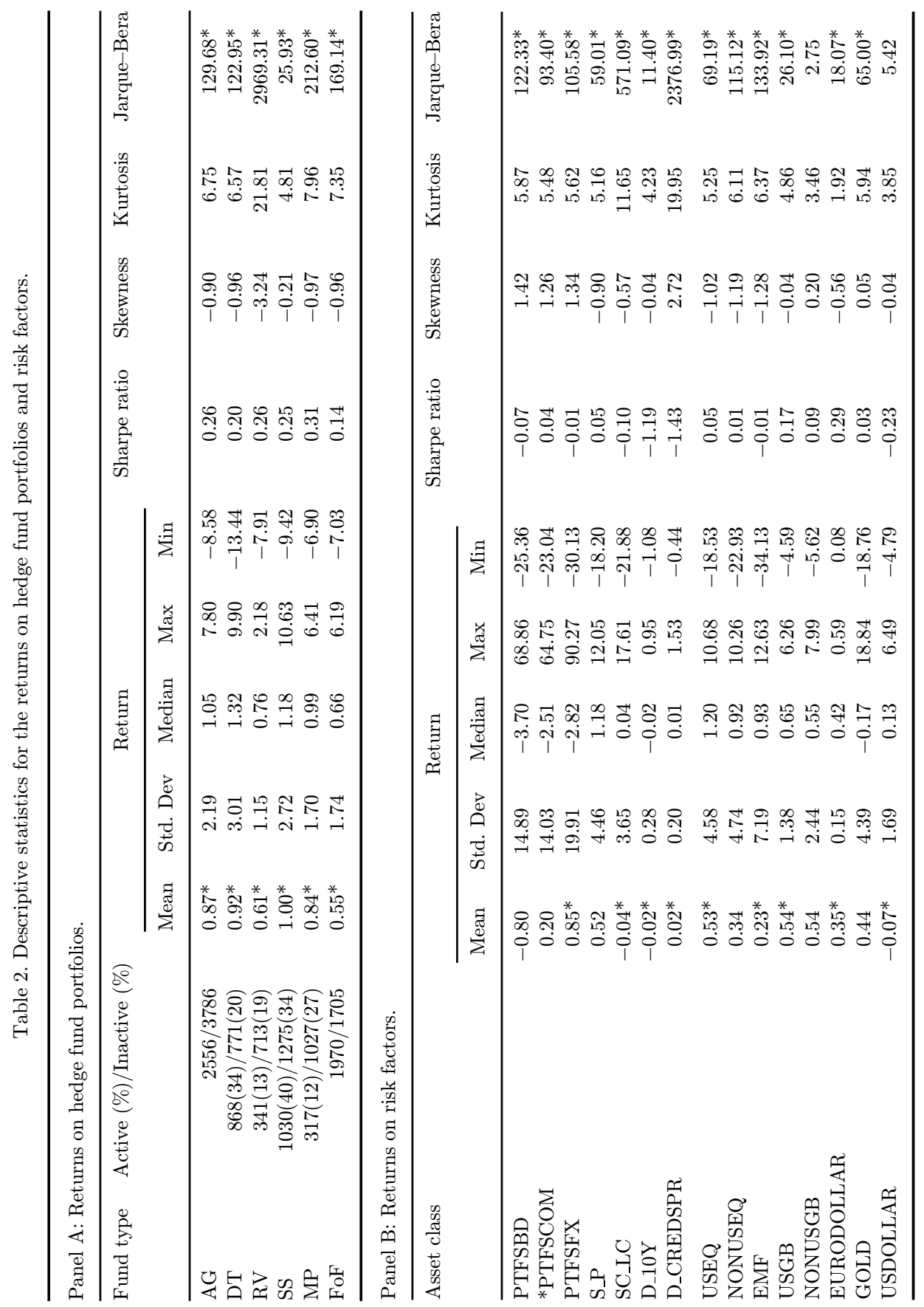




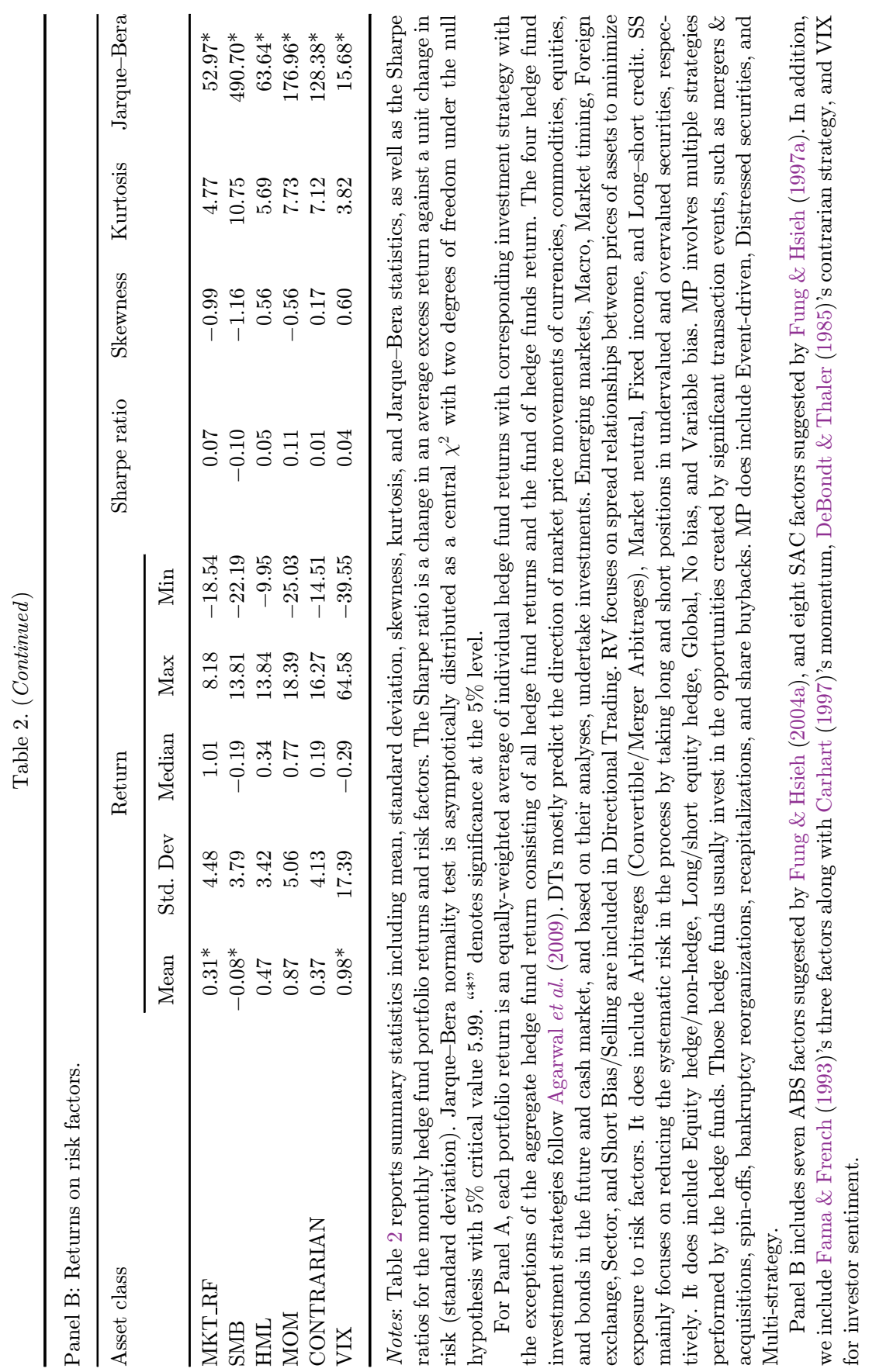


distribution of returns on hedge fund portfolios and risk factors, we may not reach the same conclusion. Higher mean returns and lower standard deviation, or higher Sharpe ratios are likely to be achieved at some costs.

\section{Econometric Methodology}

Static models with common risk factors may not be adequate in examining performance and risk exposure of all types of hedge funds. We modify and combine Jensen (1967)'s and Sharpe (1992)'s models using rolling regression analysis to estimate hedge fund performance and exposure to risk factors. To estimate performance and exposure to risk factors associated with different investment strategies, we first create four equally-weighted hedge funds portfolios based on investment strategies (DT, RV, SS, and MP), one for aggregate hedge funds (AG) and one for FoFs. These six portfolios include all monthly time series returns corresponding to investment strategy after controlling for instant history and survivorship biases. As a second step, we estimate hedge fund exposure to each of the following known risk factors: Fung and Hsieh's ABS factor and SAC factor, Carhart's four factor, contrarian strategy, and VIX. We employ the single-factor model by Jensen (1967) and Black et al. (1972):

$$
R_{i t}-R_{f t}=\alpha_{i}+\left(R_{m t}-R_{f t}\right) \beta_{i}+\varepsilon_{i t},
$$

where $i=\mathrm{AG}, \mathrm{DT}, \mathrm{RV}, \mathrm{SS}, \mathrm{MP}$, and FoF. $R_{i t}, R_{m t}$, and $R_{f t}$ denote returns on hedge fund index $i$, risk factors, and risk-free asset at time $t$, respectively. $\beta_{i}$ indicates the factor loading or exposures of returns to hedge fund indexes and to changes in risk factors. We conduct rolling regression analyses with fixed windows of 24(36)-month observations and use the adjusted $R$-squared values to examine the relation between hedge fund indexes and risk factors. The top six factors providing the highest adjusted $R$-squared values are selected for the multi-factor model to estimate hedge fund exposure to risk factors. In this way, we obtain information of unique relationships between each of the risk factors and specific investment strategies based on the adjusted $R$-squared values. Among the variables, we consider some proxy for the same or similar risk factors. For example, equity market factor (S\&P 500) among ABS factors, the US equities (MSCI North America equities) and emerging market equities among SAC factors and market are all used as proxies for the US stock market. Thus, we select one among the variables that works as a proxy for the same or similar factors.

Table 3 reports the Pearson correlation-coefficients between risk factors and groups of these risk factors from clustering based on the Pearson correlation-coefficients. The 21 risk factors are clustered into 15 groups. Risk factors clustered in the same group, especially those that proxy for equity markets are highly correlated with each other with correlation-coefficients ranging from 0.69 to 0.98 . Employing highly correlated variables as independent variables in the same model results in an increased possibility of multi-collinearity, which may lead to biased standard errors. 


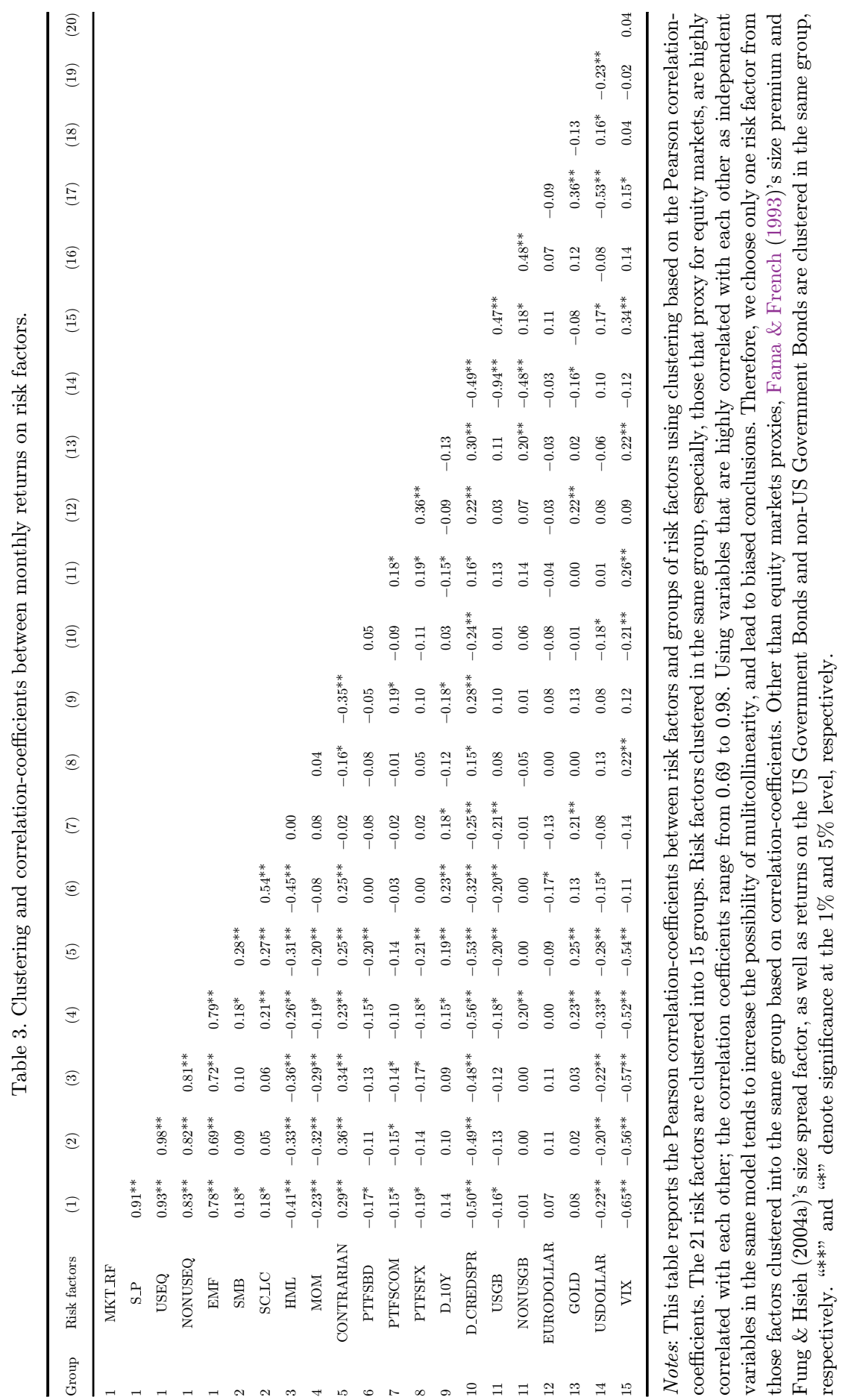


Therefore, based on their correlation-coefficients, we choose only one risk factor from the factors clustered in the same group. Other than equity market proxies, the only other two clusters are (1) Fama \& French (1993)'s size premium and Fung \& Hsieh (2004a)'s size spread factor, as well as returns on (2) US Government Bonds and nonUS Government Bonds.

As a last step, in order to simultaneously estimate hedge fund performance and exposure to specific risk factors, we extend the single-factor model into Sharpe (1992)'s multi-factor model, which considers all factors in one regression analysis:

$$
R_{i t}-R_{f t}=\alpha_{i}+\sum_{t=1}^{n}\left(X_{t}-R_{f t}\right) B_{i}+\varepsilon_{i t},
$$

where $X_{t}$ denotes vector of risk factors at time $t ; \alpha_{i}$ denotes the abnormal returns of hedge fund index $i$ and fund managers' investment skill; and $B_{i}$ denotes a vector of exposure to hedge fund index $i$ to the risk factors. $\alpha_{i}$ and $B_{i}$ are estimated by rolling regression analysis with a fixed window of 24(36)-month's observations. From the rolling $B_{i}$ based on varying windows, we can see how different hedge funds exposure to risk factors change with market conditions.

\section{Empirical Results}

\subsection{Correlation analysis between returns on hedge fund portfolios and risk factors}

Prior to estimating hedge fund performance and exposure to risk factors, we conduct correlation analysis and report the results in Table 4. Equity market-related risk factors generally exhibit high correlations with returns of hedge fund portfolios with coefficients ranging from 0.56 to 0.88 . Especially, the market risk premium and the emerging market returns appear highly correlated with returns of the six hedge fund portfolios. The VIX also has relatively high correlation with the performance of the six hedge fund portfolios. High correlation-coefficients associated with equity market-related returns and VIX indicate that investment decisions are largely based on equity market conditions or movements. As a bond-oriented risk factor, the credit spread factor exhibits a negative correlation-coefficient around -0.5 over the six hedge fund portfolios, and -0.65 for returns on RV. The highly correlated relationship between the credit spread factor and returns on RV can be attributed to investment style of RV, which maintains a certain level of return and minimizes exposure to risk. Size premium factors show a somewhat high correlation with the portfolios, especially for SS returns. Based on the results of the correlation analysis, we have a rough idea of what sort of risk factors hedge funds are exposed to.

\subsection{Rolling regression analysis of a single-factor model}

In this section, we estimate single-factor regression analyses for all available factors to select risk factors. Furthermore, we apply rolling regression analysis to a 
Table 4. Correlation-coefficients between monthly returns on hedge fund portfolios and risk factors.

\begin{tabular}{|c|c|c|c|c|c|c|c|}
\hline Group & & Agg. Hedge funds & DTs & $\mathrm{RV}$ & SS & MP & FoFs \\
\hline 1 & MKT_RF & $0.84^{* *}$ & $0.80^{* *}$ & $0.66^{* *}$ & $0.86^{* *}$ & $0.76^{* *}$ & $0.69^{* *}$ \\
\hline 1 & S_P & $0.71^{* *}$ & $0.68^{* *}$ & $0.60^{* *}$ & $0.72^{* *}$ & $0.63^{* *}$ & $0.56^{* *}$ \\
\hline 1 & USEQ & $0.73^{* *}$ & $0.70^{* *}$ & $0.61^{* *}$ & $0.74^{* *}$ & $0.65^{* *}$ & $0.58^{* *}$ \\
\hline 1 & NONUSEQ & $0.76^{* *}$ & $0.74^{* *}$ & $0.63^{* *}$ & $0.75^{* *}$ & $0.69^{* *}$ & $0.65^{* *}$ \\
\hline 1 & EMF & $0.81 * *$ & $0.88^{* *}$ & $0.60^{* *}$ & $0.76^{* *}$ & $0.72^{* *}$ & $0.72^{* *}$ \\
\hline 2 & SMB & $0.24^{* *}$ & $0.23^{* *}$ & 0.14 & $0.28^{* *}$ & $0.22^{* *}$ & $0.19^{*}$ \\
\hline 2 & SC_LC & $0.34^{* *}$ & $0.29^{* *}$ & $0.20^{* *}$ & $0.39^{* *}$ & $0.33^{* *}$ & $0.28^{* *}$ \\
\hline 3 & HML & $-0.30^{* *}$ & $-0.31^{* *}$ & -0.08 & $-0.36^{* *}$ & $-0.23^{* *}$ & $-0.19^{*}$ \\
\hline 4 & MOM & -0.02 & -0.04 & -0.06 & -0.01 & 0.02 & 0.11 \\
\hline 5 & CONTRARIAN & $0.16^{*}$ & $0.16^{*}$ & $0.23^{* *}$ & 0.14 & $0.16^{*}$ & 0.08 \\
\hline 6 & PTFSBD & $-0.20^{* *}$ & $-0.22^{* *}$ & $-0.24^{* *}$ & $-0.16^{*}$ & $-0.23^{* *}$ & $-0.24^{* *}$ \\
\hline 7 & PTFSCOM & -0.13 & -0.13 & $-0.20^{* *}$ & -0.10 & -0.13 & -0.08 \\
\hline 8 & PTFSFX & $-0.16^{*}$ & $-0.16^{*}$ & $-0.24^{* *}$ & -0.11 & -0.14 & -0.12 \\
\hline 9 & D_10Y & 0.14 & 0.14 & 0.08 & 0.14 & 0.13 & 0.11 \\
\hline 10 & D_CREDSPR & $-0.52^{* *}$ & $-0.50^{* *}$ & $-0.65^{* *}$ & $-0.45^{* *}$ & $-0.51^{* *}$ & $-0.50^{* *}$ \\
\hline 11 & USGB & -0.14 & -0.13 & -0.08 & $-0.15^{*}$ & -0.13 & -0.11 \\
\hline 11 & NONUSGB & -0.03 & -0.06 & -0.04 & -0.03 & -0.02 & -0.09 \\
\hline 12 & EURODOLLAR & $0.15^{*}$ & 0.08 & $0.22^{* *}$ & $0.16^{*}$ & $0.17^{*}$ & $0.18^{*}$ \\
\hline 13 & GOLD & $0.18^{*}$ & $0.21^{* *}$ & $0.16^{*}$ & 0.14 & 0.14 & $0.19^{*}$ \\
\hline 14 & USDOLLAR & $-0.18^{*}$ & $-0.17^{*}$ & $-0.21^{* *}$ & $-0.15^{*}$ & -0.19 & -0.14 \\
\hline 15 & VIX & $-0.51^{* *}$ & $-0.51^{* *}$ & $-0.40^{* *}$ & $-0.52^{* *}$ & $-0.44^{* *}$ & $-0.42^{* *}$ \\
\hline
\end{tabular}

Notes: This table reports correlation-coefficients between monthly returns of hedge fund portfolios by investment strategies and risk factors for the period January 1994 to December 2008. Groups are determined by clustering using Pearson correlation-coefficients. Risk factors in the same groups are likely to be highly correlated each other so that only one among those in the same groups is to be included into the model. Investment strategies for hedge fund portfolios are categorized by the four broad investment strategies (DT, RV, SS, and MP) as suggested by Aggarwal \& Jorion (2009). Similarly, we use two general categories, hedge funds and fund of hedge funds. "**" and "** denote significance at the $1 \%$ and $5 \%$ level, respectively.

single-factor model to capture the dynamic properties of hedge funds in the model. Since determination of window size in rolling regression analysis has been under debate, we utilize two different window sizes: 24 and 36 months.

Table 5 reports results from rolling regression analysis of the single-factor model by investment strategies and window size. Comparing the results from the models using the 24- and 36-month windows, the selection of appropriate risk factors should not differ significantly, so we focus the interpretation of Table 5 on the results from the 24-month window. Most of all, equity market-related factors, which account for the majority of hedge fund exposure, exhibit almost identical results in the average coefficients, adjusted $R$-squared statistics, and number of significant time frames for both window sizes. AG, DT, and FoF portfolios are the most exposed to emerging market movements. The emerging market index significantly explains the variance in the performance of these hedge funds across all time frames and shows substantially high adjusted $R$-squared statistics. Similarly, RV, SS, and MP portfolios are most exposed to Fama and French's market risk premium factor compared to the other 


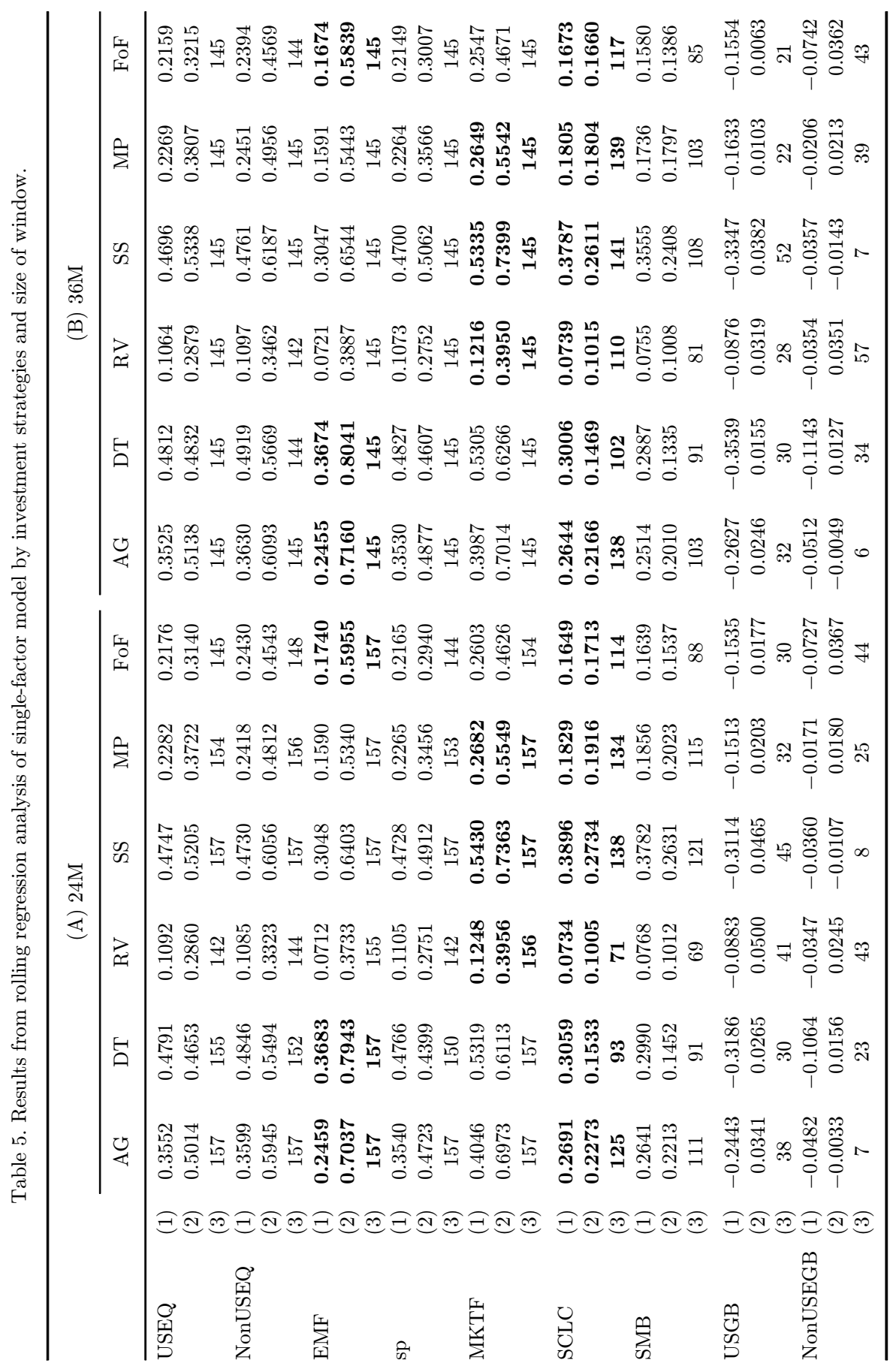




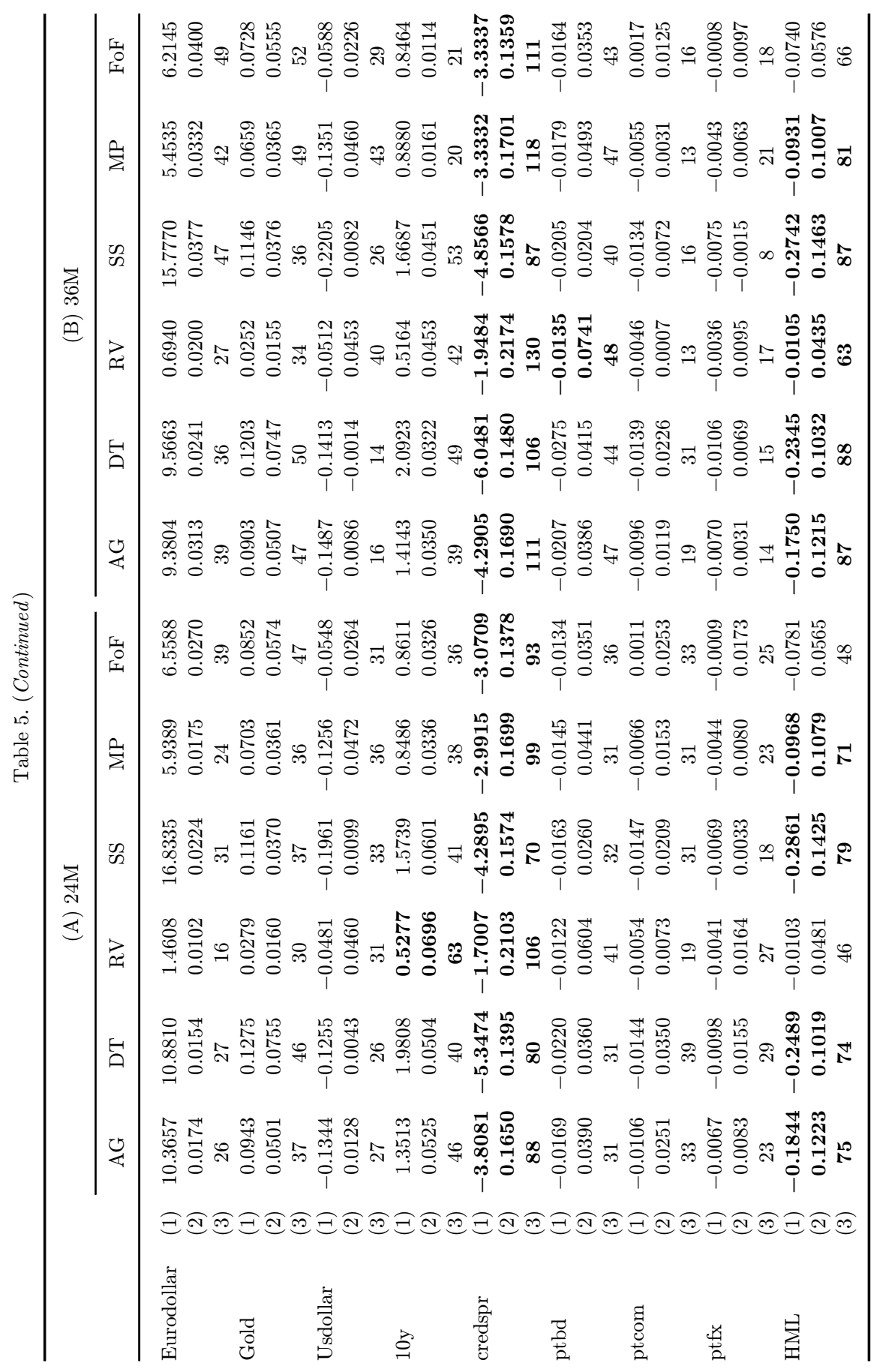




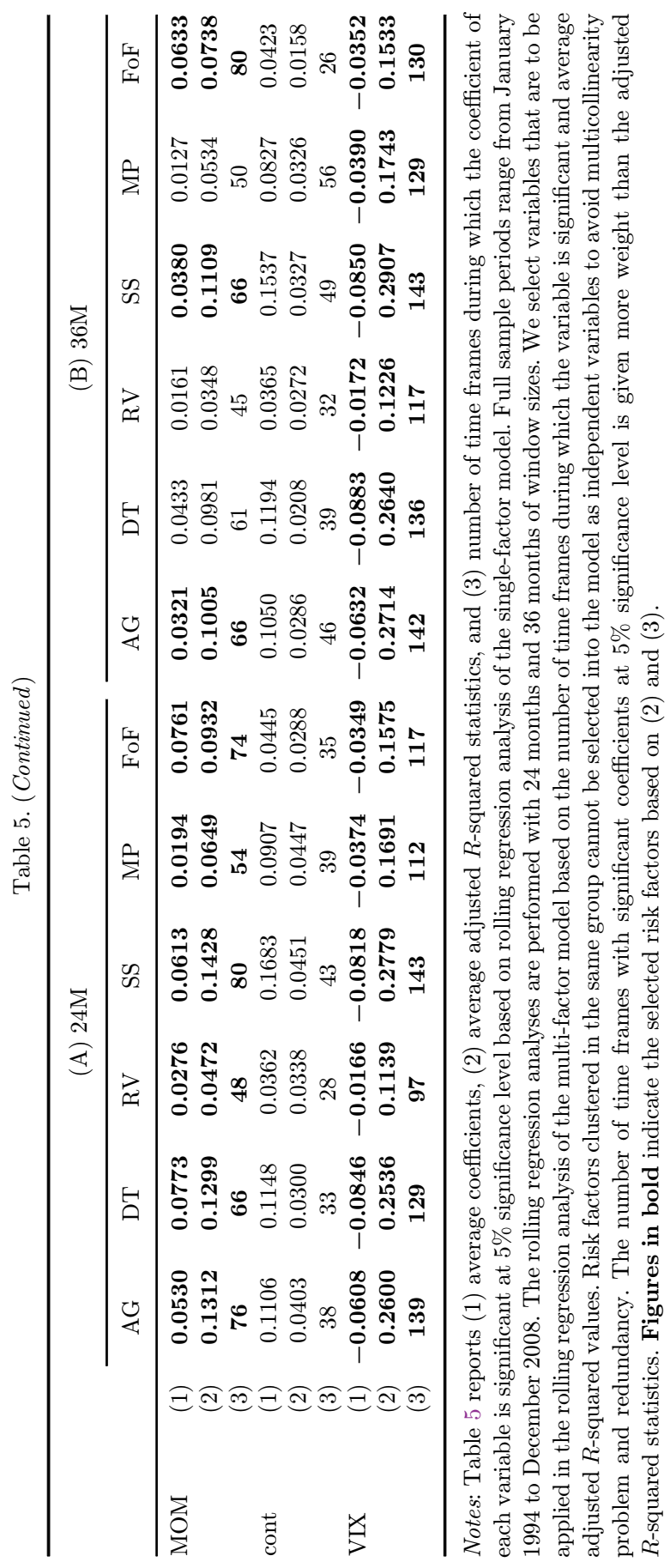


risk factors. Compared to other investment strategies, RV is more likely to pursue a stable income strategy, which accounts for its low sensitivity to changes in the market risk premium factor along with its relatively low adjusted $R$-squared statistics. As the first factor to which hedge funds are primarily exposed, we therefore select the emerging market index for AG, DT, and FoF portfolios, and Fama and French's market risk premium for RV, SS, and MP portfolios among equity marketrelated risk factors.

The VIX is the second most powerful risk factor in explaining hedge fund portfolio performance and exposure. Since the VIX increases as market uncertainty increases and investors turn to a pessimistic view about the market, it is inversely related to hedge fund performance. While all hedge fund portfolios are significantly exposed to the VIX over the majority of time frames, RV is relatively less sensitive to changes in the VIX. Instead, RV is most significantly exposed to the credit spread factor. We need to be cautious about the property of VIX measuring investor sentiment in equity markets and its relatively high correlation (from -0.52 to -0.65 ) with equity market-related factors. Therefore, using the VIX and equity marketrelated factor simultaneously in the same model may lead to a biased result and multicollinearity. Based on the average adjusted $R$-squared statistics and the number of time frames when hedge funds are significantly exposed to each risk factor, we select six risk factors. All hedge fund portfolios are exposed to a very similar set of risk factors, but the degree of the factors to which each portfolio is exposed may differ by investment strategy.

\subsection{Selection of optimal multi-factor rolling regression model}

In this section, we need to find the best combination of risk factors for different investment strategies that best explains hedge fund portfolio performance. Thus, we conduct multi-factor rolling regression analysis combining the selected risk factors from Sec. 4.2.

In Table 6, summarizing the results of the rolling regression analysis of the aggregate (AG) hedge fund portfolio, we first observe the VIX coefficients and size spread factor (SCLC), which range from positive to negative, indicating that exposure to these risk factors varies by market condition. Approximately, $75 \%$ of the variation in performance of the aggregate hedge fund portfolio is explained by a twofactor model and approximately $80 \%$ of the variation is explained by a six-factor model. As the number of factors increases, the average adjusted $R$-squared statistics and number of time frames with adjusted $R$-squared statistics greater than $70 \%$ also increase. Adding three more risk factors to the two-factor model increases the explanatory power of the model to almost $80 \%$ with 135 time frames out of 157 having $R$-squared statistics greater than $70 \%$. Although the six-factor model has slightly greater $R$-squared statistics, it does not appear large enough to warrant adding additional risk factors. For the AG portfolio, therefore, we have an optimal 
Table 6. Results from the multi-factor rolling regression analysis with 24 -month window using selected risk factors. ${ }^{c}$

\begin{tabular}{|c|c|c|c|c|c|c|c|c|c|}
\hline & $\mathrm{AG}$ & EMF & VIX & SCLC & CRED & MOM & HML & $C$ & Rsq \\
\hline \multirow[t]{5}{*}{ (1) } & Mean & 0.2402 & -0.0056 & & & & & 0.6512 & 0.7088 \\
\hline & Median & 0.2386 & -0.0030 & & & & & 0.4732 & 0.7357 \\
\hline & Min & 0.1469 & -0.0432 & & & & & -0.2981 & 0.3340 \\
\hline & $\operatorname{Max}$ & 0.3433 & 0.0366 & & & & & 1.5030 & 0.9048 \\
\hline & \#Sig. & 157 & 34 & & & & & 107 & 91 \\
\hline \multirow[t]{5}{*}{$*(2)$} & Mean & 0.2279 & & 0.1217 & & & & 0.7085 & 0.7499 \\
\hline & Median & 0.2172 & & 0.1126 & & & & 0.4639 & 0.7646 \\
\hline & Min & 0.1399 & & -0.1207 & & & & -0.2925 & 0.4380 \\
\hline & Max & 0.3340 & & 0.2785 & & & & 1.6371 & 0.9109 \\
\hline & \#Sig. & 157 & & 115 & & & & 111 & 113 \\
\hline \multirow[t]{5}{*}{ (3) } & Mean & 0.2387 & & & -0.5588 & & & 0.6892 & 0.7145 \\
\hline & Median & 0.2302 & & & -0.8433 & & & 0.4527 & 0.7566 \\
\hline & Min & 0.1408 & & & -4.4496 & & & -0.0232 & 0.3400 \\
\hline & Max & 0.3913 & & & 6.9998 & & & 1.4383 & 0.9017 \\
\hline & \#Sig. & 157 & & & 44 & & & 112 & 106 \\
\hline \multirow[t]{5}{*}{ (4) } & Mean & 0.2444 & & & & 0.0274 & & 0.6198 & 0.7198 \\
\hline & Median & 0.2368 & & & & 0.0166 & & 0.4722 & 0.7766 \\
\hline & Min & 0.1533 & & & & -0.0928 & & -0.4366 & 0.3544 \\
\hline & Max & 0.3556 & & & & 0.2065 & & 1.4838 & 0.8871 \\
\hline & \#Sig. & 157 & & & & 29 & & 113 & 109 \\
\hline \multirow[t]{5}{*}{ (5) } & Mean & 0.2399 & & & & & -0.0498 & 0.6579 & 0.7272 \\
\hline & Median & 0.2376 & & & & & -0.0150 & 0.5097 & 0.7394 \\
\hline & Min & 0.1485 & & & & & -0.3100 & -0.3607 & 0.3503 \\
\hline & $\operatorname{Max}$ & 0.3934 & & & & & 0.1561 & 1.5356 & 0.8895 \\
\hline & \#Sig. & 157 & & & & & 35 & 110 & 94 \\
\hline \multirow[t]{5}{*}{$*(6)$} & Mean & 0.2199 & -0.0058 & 0.1280 & & & & 0.6913 & 0.7571 \\
\hline & Median & 0.2185 & -0.0029 & 0.1236 & & & & 0.4666 & 0.7564 \\
\hline & Min & 0.0978 & -0.0508 & -0.1042 & & & & -0.3043 & 0.4240 \\
\hline & $\operatorname{Max}$ & 0.3334 & 0.0335 & 0.2786 & & & & 1.6426 & 0.9474 \\
\hline & \#Sig. & 157 & 36 & 115 & & & & 105 & 114 \\
\hline \multirow[t]{5}{*}{ (7) } & Mean & 0.2367 & -0.0032 & & -0.6525 & & & 0.6763 & 0.7216 \\
\hline & Median & 0.2297 & -0.0011 & & -0.8586 & & & 0.4497 & 0.7648 \\
\hline & Min & 0.1401 & -0.0432 & & -4.9936 & & & -0.0623 & 0.3487 \\
\hline & $\operatorname{Max}$ & 0.4050 & 0.0412 & & 6.6586 & & & 1.5033 & 0.9102 \\
\hline & \#Sig. & 157 & 42 & & 43 & & & 106 & 100 \\
\hline \multirow[t]{5}{*}{ (8) } & Mean & 0.2406 & -0.0046 & & & 0.0271 & & 0.6073 & 0.7256 \\
\hline & Median & 0.2364 & -0.0032 & & & 0.0148 & & 0.4654 & 0.7685 \\
\hline & Min & 0.1515 & -0.0419 & & & -0.0913 & & -0.3408 & 0.3221 \\
\hline & Max & 0.3449 & 0.0407 & & & 0.2070 & & 1.5334 & 0.9053 \\
\hline & \#Sig. & 157 & 31 & & & 29 & & 107 & 108 \\
\hline \multirow[t]{5}{*}{ (9) } & Mean & 0.2371 & -0.0040 & & & & -0.0509 & 0.6451 & 0.7306 \\
\hline & Median & 0.2319 & -0.0033 & & & & -0.0209 & 0.4718 & 0.7411 \\
\hline & Min & 0.1270 & -0.0469 & & & & -0.3229 & -0.3555 & 0.3200 \\
\hline & $\operatorname{Max}$ & 0.3886 & 0.0369 & & & & 0.1829 & 1.5659 & 0.9012 \\
\hline & \#Sig. & 157 & 33 & & & & 32 & 106 & 92 \\
\hline \multirow[t]{2}{*}{$*(10)$} & Mean & 0.2187 & -0.0022 & 0.1318 & 0.1406 & & & 0.7220 & 0.7815 \\
\hline & Median & 0.2106 & -0.0009 & 0.1258 & -0.5374 & & & 0.4382 & 0.7901 \\
\hline
\end{tabular}


Table 6. (Continued)

\begin{tabular}{|c|c|c|c|c|c|c|c|c|c|}
\hline & $\mathrm{AG}$ & $\mathrm{EMF}$ & VIX & SCLC & CRED & MOM & HML & $C$ & Rsq \\
\hline & Min & 0.1037 & -0.0510 & -0.2471 & -5.2206 & & & -0.0735 & 0.5266 \\
\hline & $\operatorname{Max}$ & 0.4105 & 0.0482 & 0.2882 & 8.1095 & & & 1.6872 & 0.9448 \\
\hline & \#Sig. & 157 & 42 & 126 & 64 & & & 99 & 125 \\
\hline \multirow[t]{5}{*}{ (11) } & Mean & 0.2196 & -0.0050 & 0.1277 & & 0.0379 & & 0.6481 & 0.7687 \\
\hline & Median & 0.2164 & -0.0023 & 0.1248 & & 0.0322 & & 0.4581 & 0.7946 \\
\hline & Min & 0.1045 & -0.0497 & -0.0632 & & -0.0612 & & -0.3075 & 0.4007 \\
\hline & Max & 0.3434 & 0.0390 & 0.3208 & & 0.1629 & & 1.6076 & 0.9486 \\
\hline & \#Sig. & 157 & 36 & 102 & & 36 & & 106 & 116 \\
\hline \multirow[t]{5}{*}{ (12) } & Mean & 0.2167 & -0.0044 & 0.1199 & & & -0.0360 & 0.6791 & 0.7658 \\
\hline & Median & 0.2105 & -0.0010 & 0.1161 & & & -0.0081 & 0.4586 & 0.7566 \\
\hline & Min & 0.0706 & -0.0495 & -0.1023 & & & -0.2701 & -0.3618 & 0.3950 \\
\hline & Max & 0.3715 & 0.0337 & 0.2985 & & & 0.1825 & 1.6856 & 0.9463 \\
\hline & \#Sig. & 157 & 37 & 94 & & & 34 & 101 & 126 \\
\hline \multirow[t]{5}{*}{ (13) } & Mean & 0.2140 & -0.0018 & 0.1326 & 0.0702 & 0.0465 & & 0.6818 & 0.7928 \\
\hline & Median & 0.2059 & -0.0012 & 0.1258 & -0.2248 & 0.0441 & & 0.4517 & 0.8183 \\
\hline & Min & 0.1022 & -0.0506 & -0.2095 & -5.4772 & -0.0677 & & -0.0568 & 0.5026 \\
\hline & $\operatorname{Max}$ & 0.3836 & 0.0625 & 0.3348 & 8.0161 & 0.1761 & & 1.6445 & 0.9461 \\
\hline & \#Sig. & 157 & 42 & 106 & 58 & 41 & & 101 & 124 \\
\hline \multirow[t]{5}{*}{$*(14)$} & Mean & 0.2102 & 0.0002 & 0.1241 & 0.0792 & & -0.0576 & 0.7197 & 0.7916 \\
\hline & Median & 0.2081 & 0.0032 & 0.1274 & -0.5674 & & -0.0274 & 0.4211 & 0.7911 \\
\hline & Min & 0.0805 & -0.0491 & -0.1839 & -5.3774 & & -0.2694 & -0.1193 & 0.5003 \\
\hline & $\operatorname{Max}$ & 0.4027 & 0.0604 & 0.3261 & 6.8525 & & 0.1059 & 1.6894 & 0.9473 \\
\hline & \#Sig. & 157 & 41 & 116 & 68 & & 41 & 94 & 135 \\
\hline \multirow[t]{5}{*}{$*(15)$} & Mean & 0.2061 & -0.0010 & 0.1207 & -0.1959 & 0.0369 & -0.0269 & 0.6762 & 0.8035 \\
\hline & Median & 0.1929 & -0.0012 & 0.1267 & -0.4126 & 0.0421 & 0.0076 & 0.4300 & 0.8181 \\
\hline & Min & 0.0869 & -0.0495 & -0.1817 & -5.2795 & -0.0835 & -0.2434 & -0.1089 & 0.4800 \\
\hline & Max & 0.3991 & 0.0605 & 0.3381 & 7.0702 & 0.1735 & 0.1872 & 1.6541 & 0.9442 \\
\hline & \#Sig. & 157 & 39 & 103 & 59 & 39 & 37 & 97 & 134 \\
\hline
\end{tabular}

Notes: This table reports results from two-factor, three-factor, four-factor, five-factor, and six-factor rolling regression analyses using as dependent variable the monthly returns on aggregate hedge fund portfolio. The sample periods are ranged from January 1994 to December 2008, and the rolling regression analyses are performed using the 24-month window. Risk factors are selected from the rolling regression analyses of the single-factor model based on the number of time frames during which coefficients are significant at $5 \%$ level and using mean $R$-squared value. The results include mean, median, minimum, and maximum regression coefficients of each variable; number of time frames during which coefficients of each variable is significant at $5 \%$ level; and mean, median, minimum, and maximum adjusted $R$-squared value, as well as number of time frames during which adjusted $R$-squared value (\#Sig.) is greater than $70 \%$. Figures in bold and "*" indicate the best models in each level that display the most stable and highest $R$-squared value based on the mean adjusted $R$-squared value and \#Sig.

${ }^{c}$ Tables A.2-A.6 are available upon request.

combination of five risk factors: emerging market equities, VIX, SCLC, credit spread factor, and HML. Brief variable descriptions are provided in Table 7.

Table A.2 summarizes the results of the rolling regression analysis of the DT portfolio and the $R$-squared statistics appear to be higher than those of the aggregate hedge fund portfolio. Even the two-factor model explains $80 \%$ of the variation in the 
Table 7. Variable description.

\begin{tabular}{ll}
\hline Variable & \multicolumn{1}{c}{ Description } \\
\hline EMF & MSCI emerging market index \\
VIX & Volatility index \\
SCLC & Size spread factor; monthly total return of Russell 2000 \\
& $\quad$ index less S\&P 500 index \\
CRED & Credit spread; monthly change in Moody's Baa yield less \\
& $\quad$ 10-year constant maturity yield \\
MOM & Momentum \\
HML & Return on value firm less return on growth firm \\
\hline
\end{tabular}

performance of the DT portfolio. Adding additional factors increases the explanatory power to approximately $84 \%$. Similarly, results of the regression analysis of the SS portfolio in Table A.4 show that approximately $83 \%$ of the variation in the portfolio's performance is explained by a two-factor model and $87 \%$ of the variation by sixfactor model. The five-factor model of the SS portfolio explains at least $70 \%$ of variation over all of 157 time frames showing that the model has a great stability in its explanatory power. It can be attributed to the investment strategies of DT and SS portfolios, which mostly rely on the equity market movements. On the contrary, results in Table A.3 displays relatively low $R$-squared statistics ranging from about $47 \%$ for the two-factor model to about $54 \%$ for the six-factor model. The number of time frames with $R$-squared statistics greater than $70 \%$ also very low. Because an RV portfolio maintains a certain level of spread to minimize risk or market exposure, it puts relatively greater weight on credit-related financial assets. The RV portfolio exhibits lower coefficients for the equity market variable, indicating less exposure to equity market movements compared to hedge fund portfolios using the other investment strategies. The RV portfolio exhibits substantially higher sensitivity to the credit spread factor relying on the movements of credit-related financial assets. For MP and FoF portfolios, the multi-factor models in Tables A.5 and A.6 account for approximately $70 \%$ of the variation. The optimal combinations of risk factors for each investment are summarized in Table 8.

AG, DT, and SS portfolios show similar compositions of risk factors. It can be attributed to, first, the characteristics of the two investment strategies, which are

Table 8. Optimal combinations of risk factors for measuring performance of hedge funds by investment strategy.

\begin{tabular}{lc}
\hline & Combination of risk factors \\
\hline AG & EMF, VIX, SCLC, CRED, HML \\
DT & EMF, VIX, SCLC, MOM \\
RV & MKT, CRED, VIX, SCLC, 10Y, MOM \\
SS & MKT, VIX, SCLC, MOM, CRED \\
MP & MKT, SCLC, VIX, CRED, HML \\
FoF & EMF, VIX, SCLC, CRED, HML \\
\hline
\end{tabular}


Table 9. Paired $t$-test of $R$-squared statistics between the selected model and the ABS-, SAC- and the four-factor models.

\begin{tabular}{lcccc}
\hline & & Opt-ABS & Opt-SAC & Opt-factor \\
\hline AG & Mean & $0.0909^{*}$ & 0.0020 & -0.0176 \\
& $t$-statistics & 6.3353 & 0.3458 & -1.9443 \\
DT & Mean & $0.2429^{*}$ & -0.0033 & $0.1492^{*}$ \\
& $t$-statistics & 14.4324 & -1.0386 & 14.5148 \\
RV & Mean & $0.0643^{*}$ & $0.0479^{*}$ & $0.0446^{*}$ \\
& $t$-statistics & 7.2488 & 3.0134 & 4.5406 \\
SS & Mean & $0.1129^{*}$ & $0.0980^{*}$ & -0.0012 \\
& $t$-statistics & 12.1288 & 8.7566 & -0.2937 \\
MP & Mean & $0.0940^{*}$ & $0.0447^{*}$ & $0.0254^{*}$ \\
& $t$-statistics & 9.7943 & 3.6611 & 5.1601 \\
FoF & Mean & $0.1772^{*}$ & -0.0154 & $0.0882^{*}$ \\
& $t$-statistics & 10.4143 & -1.2545 & 7.1976 \\
\hline
\end{tabular}

Notes: This table reports the results for testing mean differences in explanatory power (adjusted $R$-squared statistics) between our optimal model categorized by investment strategy and existing models. "*" denotes significance at the $5 \%$ level.

basically executed by predicting equity market movements. Second, AG portfolio is an average of all investment strategies and DT and SS portfolios make up $74 \%$ and $54 \%$ of active and inactive hedge funds in AG combined.

Table 9 reports paired $t$-test results and compares the explanatory power of the selected model with the ABS-factor model, SAC-factor model and Four-factor model. The mean differences of most pairs are significant indicating that the explanatory power of the selected model is greater than that of the existing models. Considering a smaller number of factors in the selected model compared to ABS- and SAC-factor models, it appears that the model customized by investment strategy is effective in improving the explanatory power and stability of the model. The mean difference between the optimal model and the SAC-factor model appears to be relatively small, so it can be considered to be almost as good as the selected model, or better than other two models. However, we must point out that the fact that the SAC-factor model simultaneously includes US equity, Non-US equity, and emerging market equity may lead to an increased multicollinearity problem. The selected optimal model provides much more reliable measure of dynamic hedge fund performance and stable, improved explanatory power.

The empirical results strongly support our research idea that hedge fund performance is better explained by a unique set of risk factors for each investment strategy. In addition, rolling regression betas are adjusted for hedge funds' dynamic and active responses to changes in market conditions by narrowing down the timevarying window. The four investment strategies exhibit the highest explanatory power with a unique set of risk factors that we find from the rolling regression 
analyses. We note that their explanatory powers are superior to those of ABS-, SACand Four-factor models.

\section{Conclusion}

In this study, we make several attempts to find the best customized models to optimally estimate hedge funds' dynamic performance and exposures by categorizing their investment strategies. We handle two types of biases: survivorship bias and instant history bias. We then select six factors that explain most of the variance in hedge fund performance conducting multi-factor rolling regression analyses using combinations of the risk factors. The optimal models consisting of the best combination of risk factors exhibit greater and more stable explanatory power compared to existing models. We observe that DT and SS portfolios are mostly exposed to equity market risk factors because their strategies are commonly based on the prediction of equity market movements. However, RV portfolios show a relatively large exposure to spread risk factors due to their investment strategy of pursuing returns while minimizing exposure to risk.

We make the following contribution to the existing literature. First, we show that hedge funds are managed in an active and dynamic manner correspondingly making it inappropriate to estimate hedge fund performance and exposure to risk factors assuming static or buy-and-hold investment strategies. Using rolling regression analysis appears to be the best way to reflect dynamic features of hedge funds when measuring hedge fund performance and risk exposures. Second, we find the optimal models that explain most of the hedge fund performance and their exposure to risk factors using investment strategy classifications. The optimal models with fewer factors exhibit greater explanatory power compared to existing models, and rolling regression analysis show that the models are more stable and credible in estimating active and dynamic management of hedge funds. We believe that our model, which is customized to a specific investment strategy, is very useful for both academic and practical purposes.

\section{Appendix A. Stability Test for Hedge Fund Exposure to the Selected Risk Factors}

We utilize rolling regression analysis to point out the weakness of existing models measuring hedge fund performance with their implicit assumption of a static investment strategy. We expect that the coefficients estimated by our rolling regression analysis will be unstable because of the active management style of hedge funds. ${ }^{\mathrm{d}}$ Therefore, the coefficients estimated from existing models should be biased.

To formally test the variation of coefficients over varying windows, we employ two different methods. First, we run a regression of the coefficients against their corresponding time periods. We have 157(145) of $\beta_{i}$ from the rolling regression

d Please refer to appendix for stability test of rolling regression betas. 
analysis with 24(36)-month window of Eq. (3.1). Then, we can define the first 24 -month as $T=1$, the second 24-month as $T=2$, and so on. The regression model to test stability of coefficients would be

$$
\beta_{i T}=C+T+T^{2}+\varphi,
$$

where $T$ is the sequence of windows from 1 to 157 for the 24 -month window and from 1 to 145 for the 36 -month window. $\beta_{i T}$ is the coefficient at each sequence. If $\beta_{i T}$ is

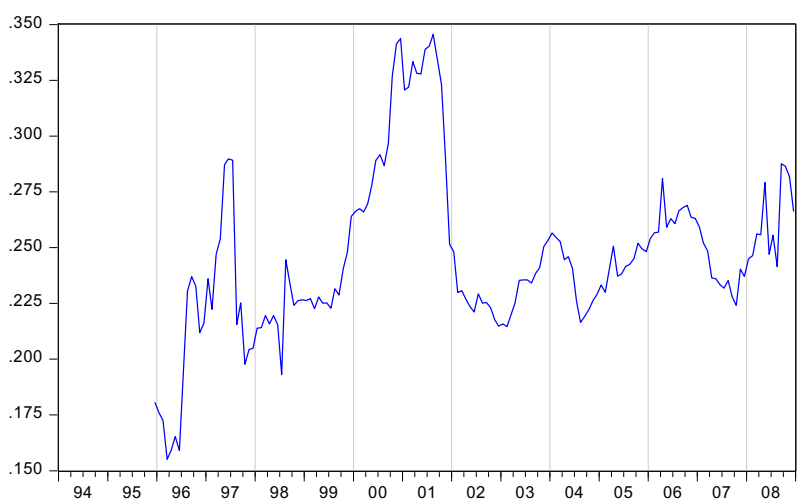

(a) Coefficients of emerging market index for aggregate HF portfolio over varying windows

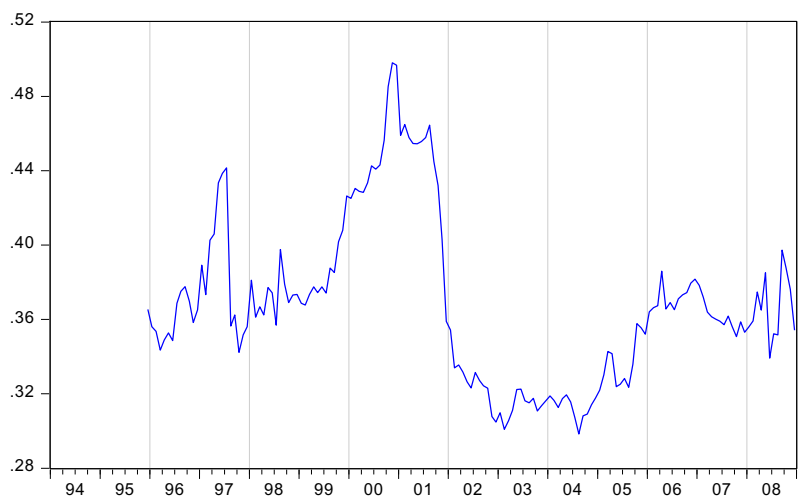

(b) Coefficients of emerging market index for DT portfolio over varying windows

Notes: These graphs intend to exhibit how actively changing exposures of hedge funds following different investment strategies are to the same risk factor. With 24-month window for rolling regression analysis, the first coefficient recorded on December 1995 is for the sample period from January 1994 to December 1995, and then, the coefficients and fixed size of windows move to right by a month. We use other risk factors for rolling regression analysis, and therefore, we need to provide with graphs for those other factors. Since equity market-related risk factor, however, takes account for significant part of hedge fund exposure to risk factors, showing instability of equity market-related factor would be sufficient to support rolling regression analysis for estimating actively managed portfolio such as hedge funds.

Fig. A.1. Coefficients of equity market-related risk factor over varying windows from rolling regression analysis of single-factor model with 24 -month window. 


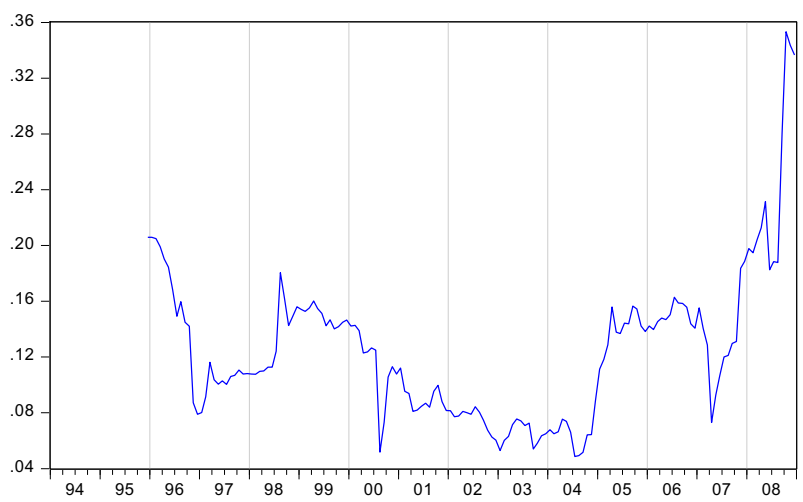

(c) Coefficients of market risk premium for RV portfolio over varying windows

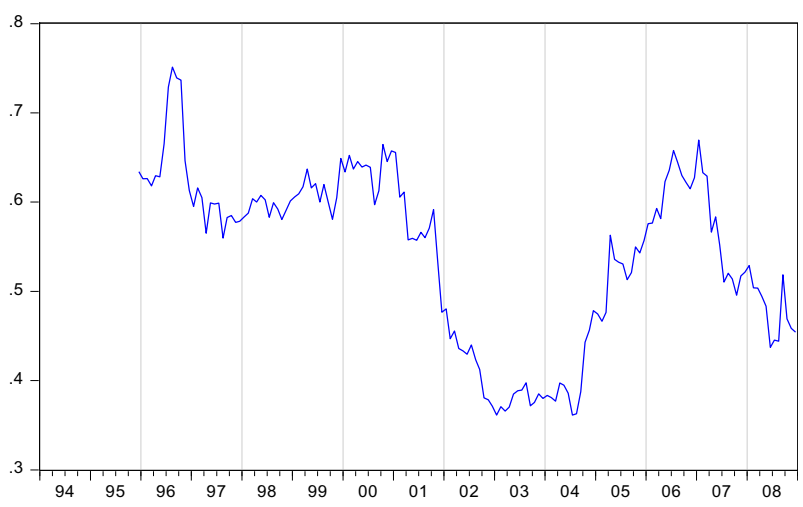

(d) Coefficients of market risk premium for SS portfolio over varying windows

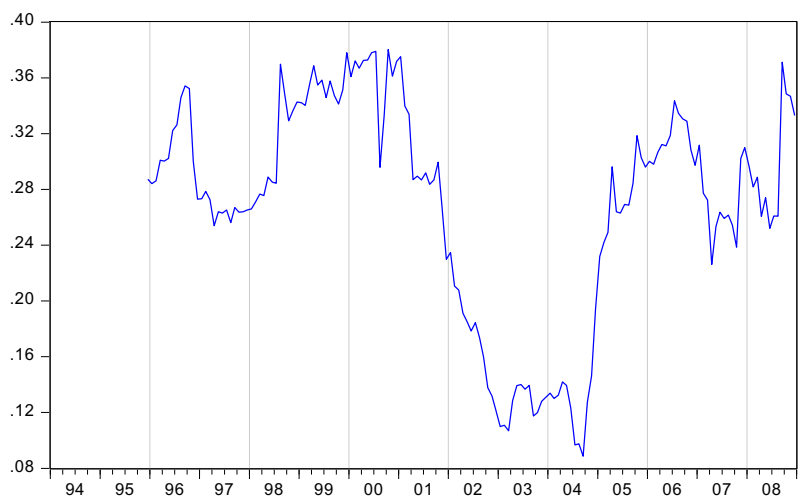

(e) Coefficients of market risk premium for MP portfolio over varying windows

Fig. A.1. (Continued) 


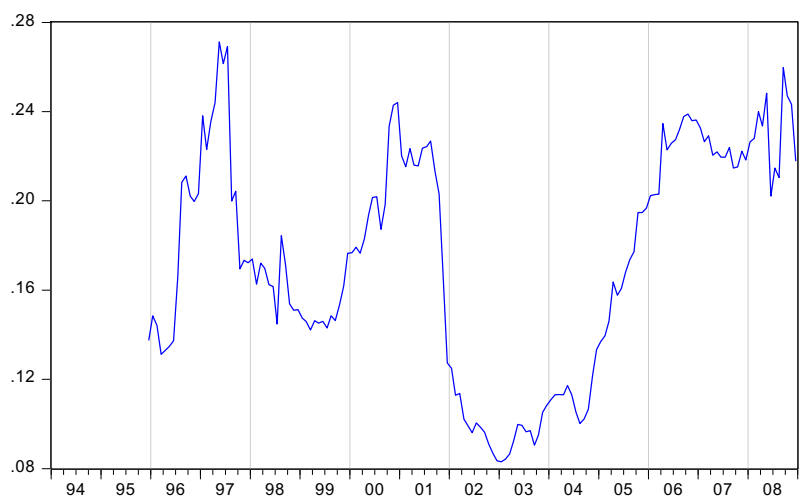

(f) Coefficients of emerging market index for FoF portfolio over varying windows

Fig. A.1. (Continued)

stable over time, $T$ and $T^{2}$ must be insignificant and zero. However, if $T$ and/or $T^{2}$ are significant, $\beta_{i T}$ will be regarded as changing over time. In this case, we reach the conclusion that coefficients of the corresponding risk factors are unstable showing that existing single factor models are inappropriate to estimate dynamic hedge fund performance.

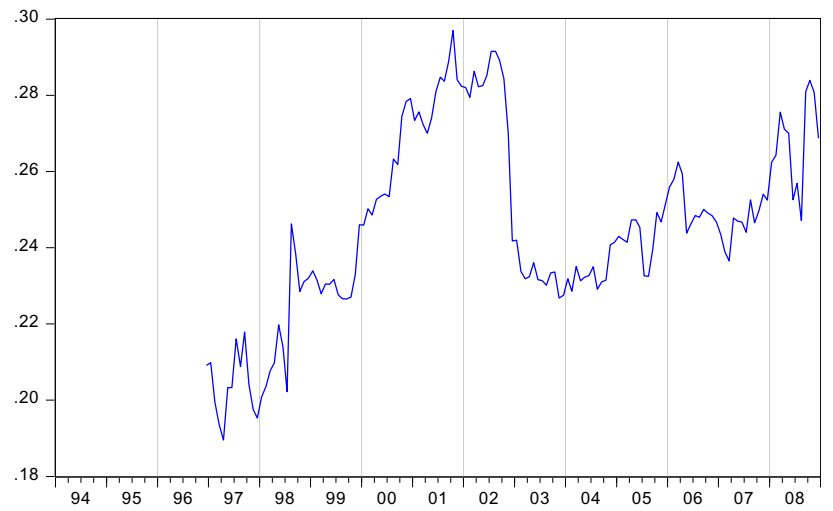

(a) Coefficients of emerging market index for aggregate HF portfolio over varying windows

Notes: These graphs intend to exhibit how actively changing exposures of hedge funds following different investment strategies are to the same risk factor. With 36-month window for rolling regression analysis, the first coefficient recorded on December 1996 is for the sample period from January 1994 to December 1996, and then, the coefficients and fixed size of windows move to right by a month. We use other risk factors for rolling regression analysis, and therefore, we need to provide with graphs for those other factors. Since equity market-related risk factor, however, takes account for significant part of hedge fund exposure to risk factors, showing instability of equity market-related factor would be sufficient to support rolling regression analysis for estimating actively managed portfolio such as hedge funds.

Fig. A.2. Coefficients of equity market-related risk factor over varying windows from rolling regression analysis of single-factor model with 36 -month window. 


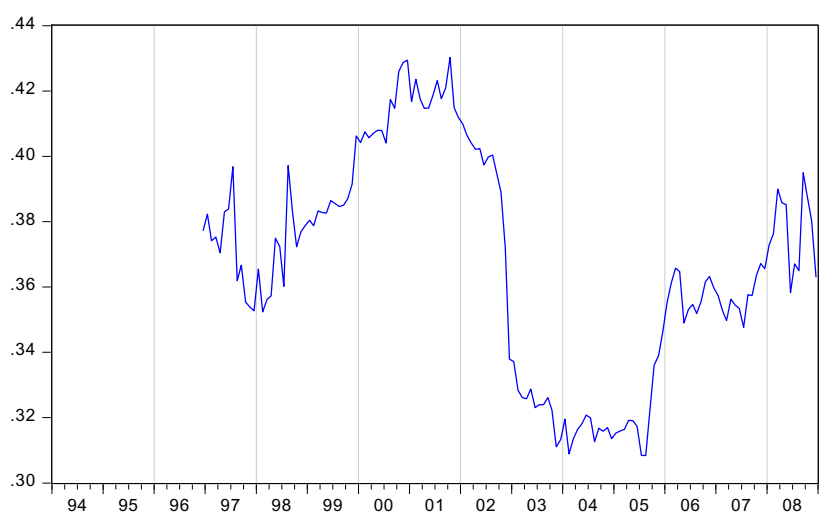

(b) Coefficients of emerging market index for DT portfolio over varying windows

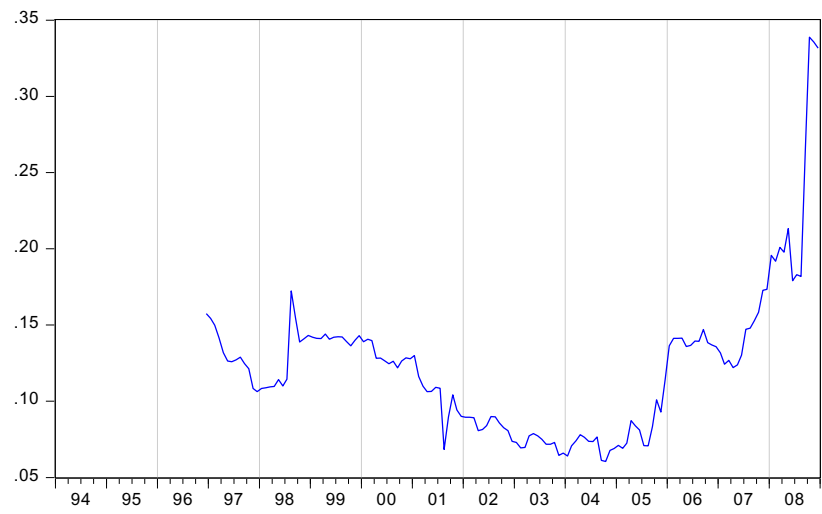

(c) Coefficients of market risk premium for RV portfolio over varying windows

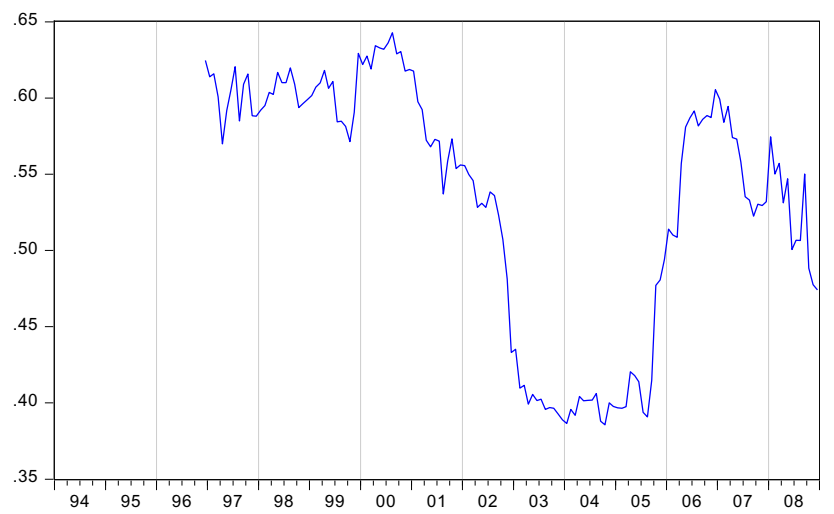

(d) Coefficients of market risk premium for SS portfolio over varying windows

Fig. A.2. (Continued) 


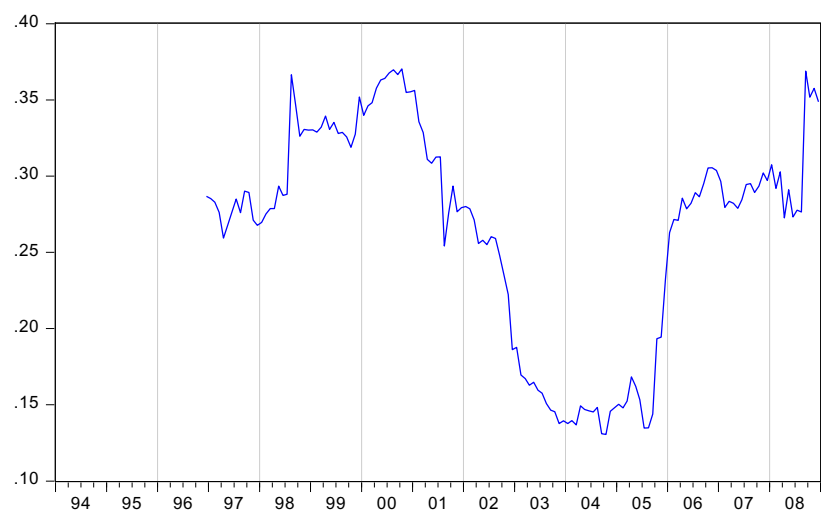

(e) Coefficients of market risk premium for MP portfolio over varying windows

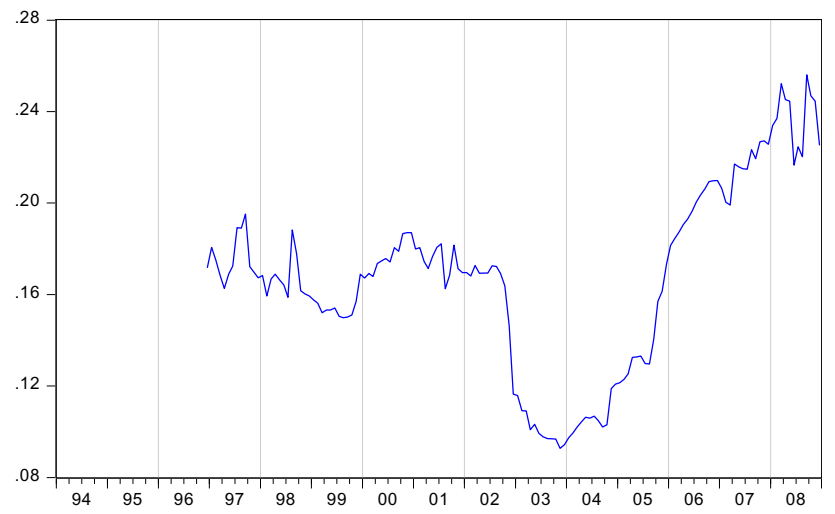

(f) Coefficients of emerging market index for FoF portfolio over varying windows

Fig. A.2. (Continued)

Table A.1 reports the results of the regression analysis of the coefficients of equity market-related risk factor against time, $T$. With a single exception of coefficients for DT, all the coefficients of both 24- and 36-month windows for hedge fund portfolios exhibit linear and quadratic relationships across time, T. Even DT, the only exception, displays a linear relationship. Although coefficients of $T$ and $T^{2}$ are very low, they are significantly different from zero so that the $\beta_{i T} \mathrm{~s}$ in every sequence are also significantly different from each other. It indicates that the coefficients have a significant pattern over time, and therefore, we may consider the coefficients to be unstable over time. As a second approach to showing the instability of coefficients for a single-factor rolling regression analysis, we utilize a method of recursive residuals. Recall our single-factor regression model of Eq. (3.1): $R_{i t}-R_{f t}=\alpha_{i}+$ $\left(R_{m t}-R_{f t}\right) \beta_{i}+\varepsilon_{i t}$, and substitute $R_{i t}-R_{f t}$ with $y_{t}$ and $R_{m t}-R_{f t}$ with $x_{t}$. Then, 
Table A.1. Stability tests for coefficients of equity market-related risk factors from rolling regression analysis of single-factor model.

\begin{tabular}{|c|c|c|c|c|c|c|}
\hline & \multicolumn{3}{|c|}{$24 \mathrm{M}$} & \multicolumn{3}{|c|}{$36 \mathrm{M}$} \\
\hline & $C$ & $T$ & $T^{2}$ & C & $T$ & $T^{2}$ \\
\hline $\mathrm{AG}$ & $\begin{array}{l}0.2297^{*} \\
0.2024^{*}\end{array}$ & $\begin{array}{l}2.05 \mathrm{E}-04^{*} \\
1.24 \mathrm{E}-03^{*}\end{array}$ & $-6.53 \mathrm{E}-06^{*}$ & $\begin{array}{l}0.2274^{*} \\
0.2066^{*}\end{array}$ & $\begin{array}{l}2.49 \mathrm{E}-04^{*} \\
1.10 \mathrm{E}-03^{*}\end{array}$ & $-5.81 \mathrm{E}-06^{*}$ \\
\hline DT & $\begin{array}{l}0.3910^{*} \\
0.3909^{*}\end{array}$ & $\begin{array}{l}-2.87 \mathrm{E}-04^{*} \\
-2.84 \mathrm{E}-04^{*}\end{array}$ & $-2.02 \mathrm{E}-08$ & $\begin{array}{l}0.3901^{*} \\
0.3966^{*}\end{array}$ & $\begin{array}{l}-3.11 \mathrm{E}-04^{*} \\
-5.78 \mathrm{E}-04^{*}\end{array}$ & $1.83 \mathrm{E}-06$ \\
\hline $\mathrm{RV}$ & $\begin{array}{l}0.1064^{*} \\
0.1916^{*}\end{array}$ & $\begin{array}{r}2.33 \mathrm{E}-04^{*} \\
-2.98 \mathrm{E}-03^{*}\end{array}$ & $2.04 \mathrm{E}-05^{*}$ & $\begin{array}{l}0.1022^{*} \\
0.1826^{*}\end{array}$ & $\begin{array}{r}2.66 \mathrm{E}-04^{*} \\
-3.02 \mathrm{E}-03^{*}\end{array}$ & $2.25 \mathrm{E}-05^{*}$ \\
\hline SS & $\begin{array}{l}0.6206^{*} \\
0.7000^{*}\end{array}$ & $\begin{array}{l}-9.83 \mathrm{E}-04^{*} \\
-3.98 \mathrm{E}-03^{*}\end{array}$ & $1.90 \mathrm{E}-05^{*}$ & $\begin{array}{l}0.6022^{*} \\
0.6810^{*}\end{array}$ & $\begin{array}{l}-9.41 \mathrm{E}-04^{*} \\
-4.16 \mathrm{E}-03^{*}\end{array}$ & $2.20 \mathrm{E}-05^{*}$ \\
\hline MP & $\begin{array}{l}0.3002^{*} \\
0.3626^{*}\end{array}$ & $\begin{array}{l}-4.05 \mathrm{E}-04^{*} \\
-2.76 \mathrm{E}-03^{*}\end{array}$ & $1.49 \mathrm{E}-05^{*}$ & $\begin{array}{l}0.2992^{*} \\
0.3680^{*}\end{array}$ & $\begin{array}{l}-4.70 \mathrm{E}-04^{*} \\
-3.28 \mathrm{E}-03^{*}\end{array}$ & $1.92 \mathrm{E}-05^{*}$ \\
\hline FoF & $\begin{array}{l}0.1593^{*} \\
0.2189^{*}\end{array}$ & $\begin{array}{r}1.85 \mathrm{E}-04^{*} \\
-2.06 \mathrm{E}-03^{*}\end{array}$ & $1.42 \mathrm{E}-05^{*}$ & $\begin{array}{l}0.1473^{*} \\
0.2063^{*}\end{array}$ & $\begin{array}{r}2.75 \mathrm{E}-04^{*} \\
-2.13 \mathrm{E}-03^{*}\end{array}$ & $1.65 \mathrm{E}-05^{*}$ \\
\hline
\end{tabular}

Notes: This table reports the results from stability tests for coefficients of equity marketrelated risk factors from rolling regression analysis of the single-factor model. The testing models are $\beta_{i T}=C+T+\varphi$ and $\beta_{i T}=C+T+T^{2}+\varphi$, where $T$ denotes the sequence of window from 1 to 157 for 24 -month window and 1 to 145 for 36 -month window, as well as the $\beta_{i T}$ is the coefficient at each sequence. "*" indicates significance at the $5 \%$ level.

we have a standard simple linear regression model: $y_{t}=\beta \cdot x_{t}+\varepsilon_{t}$, where $\varepsilon_{t} \sim$ iid $N\left(0, \sigma^{2}\right)$ and $t=1, \ldots, T$. Instead of using the entire sample period, we estimate with the first $k$ observations, $k+1$ observations, and $k+n$. This procedure provides us with recursive coefficients, $\hat{\beta}_{t}$. At each time period $t, t=k, \ldots, T-1$, we can forecast the next time period $t+1$, and express as $\hat{y}_{t+1, t}=\hat{\beta}_{t} \cdot x_{t+1}$. The forecasting errors or recursive residuals are expressed as $\hat{e}_{t+1, t}=y_{t+1}-\hat{y}_{t+1, t}$. The variance of the recursive residuals changes as the number of observations increases from $k$ through $T$, because the model is estimated more precisely as the sample size increases. The recursive residuals are reported in the form of graph with two standard error bands. The recursive residuals outside the bands indicate instability of coefficients.

Other than the recursive residuals, we consider the standardized recursive residuals as $w_{t+1, t} \equiv \frac{\hat{e}_{t+1, t}}{\sigma \sqrt{r_{t}}}$, where $t=k, \ldots, T-1$. The cumulative sum (CUSUM) of the standardized recursive residuals is one of the methods to test parameter stability. Because $w_{t+1, t} \sim$ iid $N(0,1)$, CUSUM is just a sum of iid $N(0,1)$ random variables, and express as $\mathrm{CUSUM}_{t} \equiv \sum_{\tau=k}^{t} w_{\tau+1, \tau}, t=k, \ldots, T-1$. CUSUM is reported with its $95 \%$ probability bounds in the graph. CUSUM outside the bounds indicates parameter instability.

Figure A.3 displays the results of stability tests on the coefficients for the equity market-related risk factors using recursive residuals. Each row of figures includes 

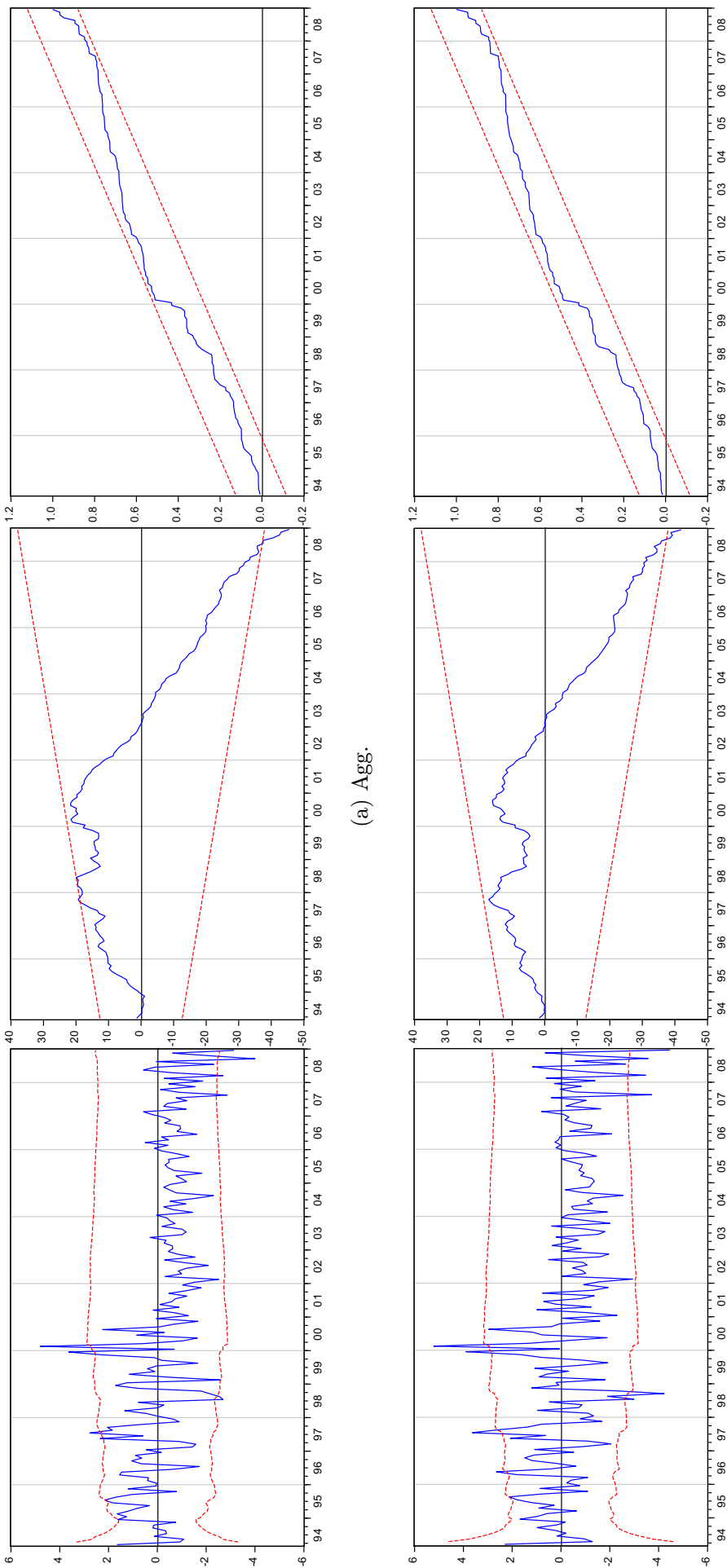

水.尹

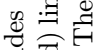

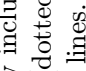

萬莡

웡

되

蛋节

晃

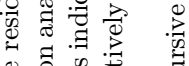

Q

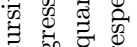

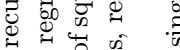

$\infty$ ठำ

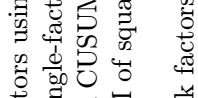

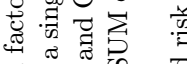

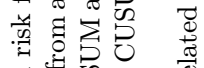

च

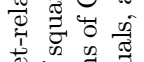

क्ष

范范范

붕

00
00
4

อ

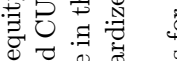

0

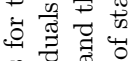

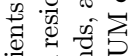

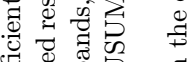

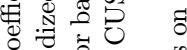

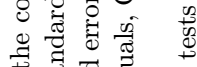

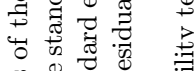

of

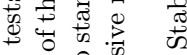

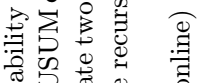

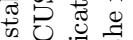

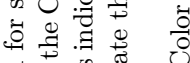

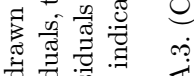

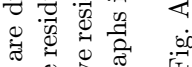

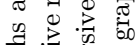

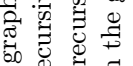

ष

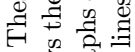

نे क्ष

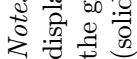



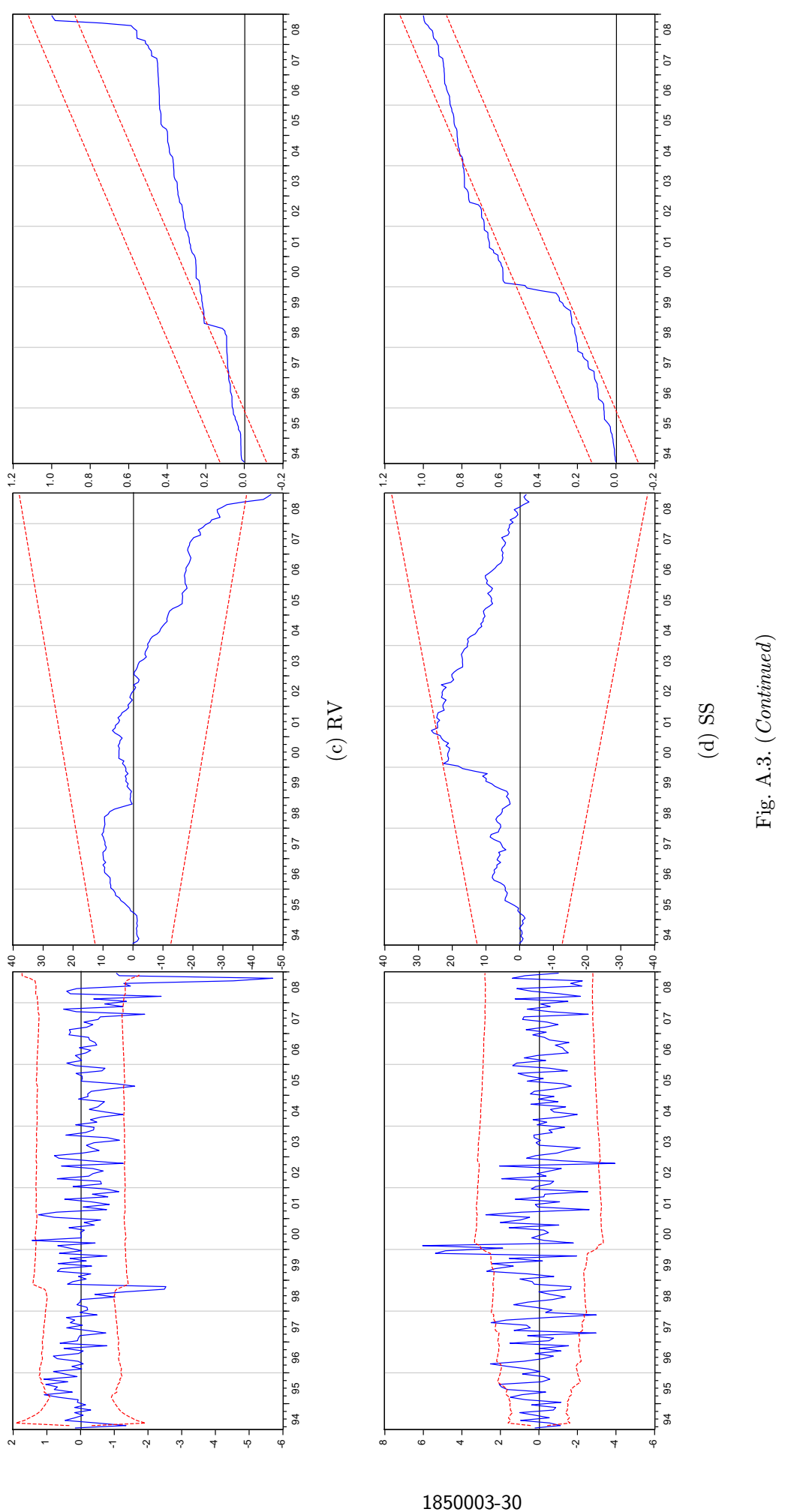

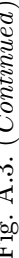



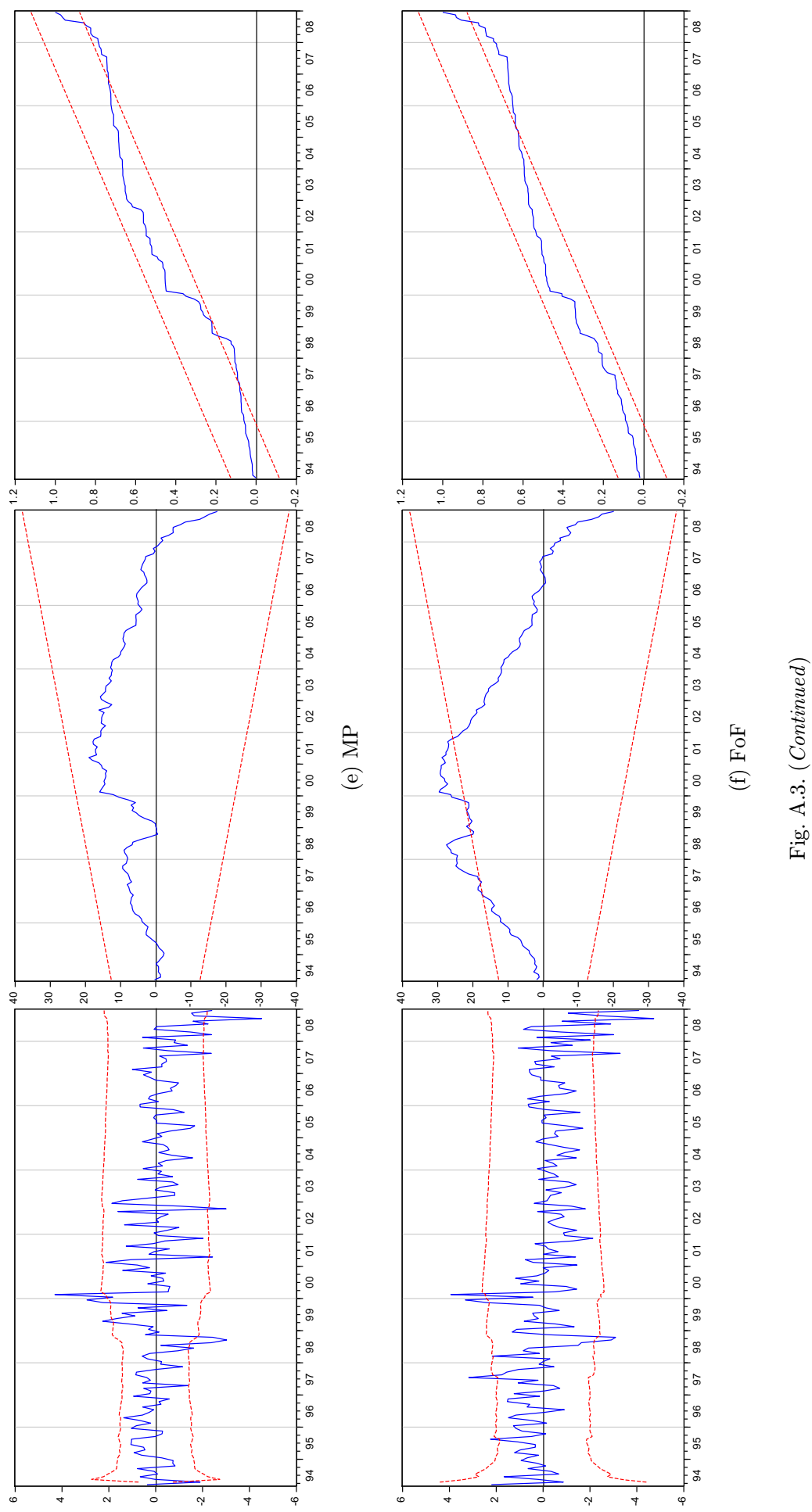

1850003-31 
Table A.2. Results from the multi-factor rolling regression analysis with 24-month window using selected risk factors.

\begin{tabular}{|c|c|c|c|c|c|c|c|c|c|}
\hline & DT & EMF & VIX & SCLC & CRED & HML & MOM & C & Rsq \\
\hline \multirow[t]{5}{*}{$*(1)$} & Mean & 0.3697 & -0.0018 & & & & & 0.6930 & 0.8084 \\
\hline & Median & 0.3821 & 0.0043 & & & & & 0.5401 & 0.8088 \\
\hline & Min & 0.2181 & -0.0644 & & & & & -0.2504 & 0.5573 \\
\hline & Max & 0.4881 & 0.0393 & & & & & 1.7220 & 0.9363 \\
\hline & \#Sig. & 157 & 63 & & & & & 107 & 140 \\
\hline \multirow[t]{5}{*}{ (2) } & Mean & 0.3574 & & 0.0748 & & & & 0.7501 & 0.8032 \\
\hline & Median & 0.3534 & & 0.0802 & & & & 0.5456 & 0.8253 \\
\hline & Min & 0.2811 & & -0.2666 & & & & -0.1995 & 0.5071 \\
\hline & Max & 0.4908 & & 0.2673 & & & & 1.7032 & 0.9185 \\
\hline & \#Sig. & 157 & & 31 & & & & 109 & 139 \\
\hline \multirow[t]{5}{*}{ (3) } & Mean & 0.3652 & & & -0.5948 & & & 0.7578 & 0.7965 \\
\hline & Median & 0.3560 & & & -0.5226 & & & 0.5938 & 0.8159 \\
\hline & Min & 0.2588 & & & -6.6748 & & & -0.0427 & 0.4940 \\
\hline & $\operatorname{Max}$ & 0.5180 & & & 5.0950 & & & 1.6246 & 0.9212 \\
\hline & \#Sig. & 157 & & & 27 & & & 113 & 135 \\
\hline \multirow[t]{5}{*}{ (4) } & Mean & 0.3654 & & & & -0.0308 & & 0.7236 & 0.7987 \\
\hline & Median & 0.3606 & & & & -0.0248 & & 0.5505 & 0.8084 \\
\hline & Min & 0.2667 & & & & -0.2736 & & -0.3343 & 0.5605 \\
\hline & $\operatorname{Max}$ & 0.5386 & & & & 0.1946 & & 1.6909 & 0.9177 \\
\hline & \#Sig. & 157 & & & & 20 & & 105 & 142 \\
\hline \multirow[t]{5}{*}{ (5) } & Mean & 0.3661 & & & & & 0.0380 & 0.6703 & 0.8043 \\
\hline & Median & 0.3623 & & & & & 0.0267 & 0.5738 & 0.8347 \\
\hline & Min & 0.2738 & & & & & -0.0831 & -0.4691 & 0.4930 \\
\hline & $\operatorname{Max}$ & 0.4752 & & & & & 0.2218 & 1.6259 & 0.9152 \\
\hline & \#Sig. & 157 & & & & & 37 & 104 & 136 \\
\hline \multirow[t]{5}{*}{$*(6)$} & Mean & 0.3534 & -0.0028 & 0.0888 & & & & 0.7158 & 0.8187 \\
\hline & Median & 0.3687 & 0.0034 & 0.0874 & & & & 0.5459 & 0.8287 \\
\hline & Min & 0.1668 & -0.0715 & -0.2585 & & & & -0.2981 & 0.5459 \\
\hline & $\operatorname{Max}$ & 0.4752 & 0.0338 & 0.2706 & & & & 1.7473 & 0.9434 \\
\hline & \#Sig. & 157 & 61 & 47 & & & & 99 & 142 \\
\hline \multirow[t]{5}{*}{ (7) } & Mean & 0.3675 & -0.0008 & & -0.8382 & & & 0.7267 & 0.8130 \\
\hline & Median & 0.3696 & 0.0037 & & -0.8342 & & & 0.5660 & 0.8241 \\
\hline & Min & 0.2187 & -0.0644 & & -6.7767 & & & -0.1119 & 0.5394 \\
\hline & $\operatorname{Max}$ & 0.5111 & 0.0408 & & 4.7347 & & & 1.7203 & 0.9349 \\
\hline & \#Sig. & 157 & 68 & & 32 & & & 108 & 139 \\
\hline \multirow[t]{5}{*}{ (8) } & Mean & 0.3698 & -0.0009 & & & -0.0347 & & 0.6920 & 0.8119 \\
\hline & Median & 0.3753 & 0.0064 & & & -0.0257 & & 0.5517 & 0.8098 \\
\hline & Min & 0.1941 & -0.0630 & & & -0.2884 & & -0.3024 & 0.5844 \\
\hline & $\operatorname{Max}$ & 0.5154 & 0.0427 & & & 0.1868 & & 1.7513 & 0.9332 \\
\hline & \#Sig. & 157 & 61 & & & 18 & & 104 & 144 \\
\hline \multirow[t]{5}{*}{ (9) } & Mean & 0.3695 & -0.0010 & & & & 0.0394 & 0.6382 & 0.8186 \\
\hline & Median & 0.3767 & 0.0054 & & & & 0.0258 & 0.5351 & 0.8443 \\
\hline & Min & 0.2386 & -0.0620 & & & & -0.0739 & -0.4114 & 0.5380 \\
\hline & Max & 0.4835 & 0.0390 & & & & 0.2229 & 1.7201 & 0.9334 \\
\hline & \#Sig. & 157 & 60 & & & & 36 & 100 & 140 \\
\hline \multirow[t]{2}{*}{ (10) } & Mean & 0.3525 & -0.0012 & 0.0868 & -0.4027 & & & 0.7545 & 0.8259 \\
\hline & Median & 0.3541 & 0.0039 & 0.0938 & -0.2925 & & & 0.5627 & 0.8378 \\
\hline
\end{tabular}


Table A.2. (Continued)

\begin{tabular}{|c|c|c|c|c|c|c|c|c|c|}
\hline & DT & $\mathrm{EMF}$ & VIX & SCLC & CRED & HML & MOM & $C$ & Rsq \\
\hline & Min & 0.1678 & -0.0715 & -0.3649 & -6.7892 & & & -0.1582 & 0.5221 \\
\hline & Max & 0.5250 & 0.0400 & 0.2909 & 7.3906 & & & 1.7529 & 0.9405 \\
\hline & \#Sig. & 157 & 64 & 58 & 37 & & & 100 & 140 \\
\hline \multirow[t]{5}{*}{ (11) } & Mean & 0.3524 & -0.0020 & 0.0844 & & -0.0223 & & 0.7108 & 0.8196 \\
\hline & Median & 0.3629 & 0.0061 & 0.0786 & & -0.0203 & & 0.5398 & 0.8252 \\
\hline & Min & 0.1068 & -0.0667 & -0.2579 & & -0.2515 & & -0.3480 & 0.5626 \\
\hline & Max & 0.5024 & 0.0374 & 0.2648 & & 0.1871 & & 1.7608 & 0.9628 \\
\hline & \#Sig. & 157 & 63 & 41 & & 18 & & 102 & 143 \\
\hline \multirow[t]{5}{*}{$*(12)$} & Mean & 0.3532 & -0.0021 & 0.0870 & & & 0.0466 & 0.6644 & 0.8261 \\
\hline & Median & 0.3670 & 0.0048 & 0.0781 & & & 0.0504 & 0.5334 & 0.8458 \\
\hline & Min & 0.1703 & -0.0709 & -0.1866 & & & -0.0867 & -0.3132 & 0.5253 \\
\hline & Max & 0.4822 & 0.0376 & 0.3061 & & & 0.1715 & 1.7172 & 0.9410 \\
\hline & \#Sig. & 157 & 59 & 43 & & & 32 & 95 & 141 \\
\hline \multirow[t]{5}{*}{ (13) } & Mean & 0.3464 & 0.0000 & 0.0828 & -0.5762 & -0.0429 & & 0.7582 & 0.8260 \\
\hline & Median & 0.3441 & 0.0051 & 0.0871 & -0.1453 & -0.0297 & & 0.5723 & 0.8351 \\
\hline & Min & 0.1232 & -0.0663 & -0.3402 & -8.0715 & -0.2469 & & -0.2243 & 0.5384 \\
\hline & $\operatorname{Max}$ & 0.5309 & 0.0399 & 0.2776 & 5.9050 & 0.1392 & & 1.7785 & 0.9621 \\
\hline & \#Sig. & 157 & 63 & 47 & 37 & 16 & & 107 & 141 \\
\hline \multirow[t]{5}{*}{$*(14)$} & Mean & 0.3465 & -0.0008 & 0.0861 & -0.5189 & 0.0508 & & 0.7107 & 0.8326 \\
\hline & Median & 0.3544 & 0.0062 & 0.0807 & -0.3497 & 0.0610 & & 0.5945 & 0.8566 \\
\hline & Min & 0.1676 & -0.0709 & -0.2937 & -6.8778 & -0.0870 & & -0.1306 & 0.4994 \\
\hline & $\operatorname{Max}$ & 0.5250 & 0.0513 & 0.3341 & 7.2632 & 0.1667 & & 1.7221 & 0.9377 \\
\hline & \#Sig. & 157 & 63 & 48 & 37 & 35 & & 99 & 139 \\
\hline \multirow[t]{5}{*}{$*(15)$} & Mean & 0.3434 & -0.0017 & 0.0742 & -1.0075 & -0.0061 & 0.0532 & 0.6975 & 0.8372 \\
\hline & Median & 0.3457 & 0.0037 & 0.0786 & -0.9442 & 0.0046 & 0.0658 & 0.5952 & 0.8598 \\
\hline & Min & 0.1316 & -0.0659 & -0.3090 & -7.9971 & -0.2589 & -0.1075 & -0.2075 & 0.5116 \\
\hline & Max & 0.5527 & 0.0391 & 0.3180 & 5.8432 & 0.2869 & 0.2151 & 1.7327 & 0.9631 \\
\hline & \#Sig. & 157 & 64 & 44 & 34 & 28 & 40 & 108 & 141 \\
\hline
\end{tabular}

Notes: This table reports the results from the two-factor, three-factor, four-factor, five-factor, and sixfactor rolling regression analyses using as dependent variable the monthly returns on the DT portfolio. The sample period ranges from January 1994 to December 2008, and the rolling regression analyses are performed using the 24-month window. Risk factors in this table are selected from the rolling regression analyses of the single-factor model based on the number of time frames during which coefficients are significant at $5 \%$ significance level based on the mean $R$-squared value. The results include mean, median, minimum, and maximum regression coefficients of each variable; number of time frames during which coefficients of each variable is significant at the $5 \%$ significance level; and mean, median, minimum, and maximum adjusted $R$-squared value, as well as number of time frames during which adjusted $R$-squared value (\#Sig.) is greater than 70\%. Figures in bold and "*” indicate the best models in each level that show the most stable and highest $R$-squared value based on the mean adjusted $R$-squared value and \#Sig.

figures of the recursive residuals, the CUSUM of the standardized residuals and CUSUM of squares from a single-factor regression analysis, respectively. Analyzing the figures in the first row for the aggregate hedge fund portfolio, recursive residual, CUSUM and CUSUM of squares mostly stay within the $95 \%$ critical bounds. However, we can observe out of bound values for some periods. Those periods include Asian Financial Crisis in 1997-1998, the Dot.com bubble around 2000, and 
Table A.3. Results from the multi-factor rolling regression analysis with 24-month window using selected risk factors.

\begin{tabular}{|c|c|c|c|c|c|c|c|c|c|}
\hline & $\mathrm{RV}$ & MKT & CRED & VIX & SCLC & $10 y$ & MOM & $C$ & Rsq \\
\hline \multirow[t]{5}{*}{$*(1)$} & Mean & 0.0966 & -1.5351 & & & & & 0.3876 & 0.4672 \\
\hline & Median & 0.1059 & -1.0057 & & & & & 0.3646 & 0.4517 \\
\hline & Min & -0.0045 & -5.0119 & & & & & 0.0623 & 0.0719 \\
\hline & Max & 0.1985 & 1.1970 & & & & & 0.9079 & 0.8890 \\
\hline & \#Sig. & 128 & 70 & & & & & 128 & 11 \\
\hline \multirow[t]{5}{*}{ (2) } & Mean & 0.1407 & & 0.0051 & & & & 0.3346 & 0.3904 \\
\hline & Median & 0.1376 & & 0.0030 & & & & 0.3173 & 0.3851 \\
\hline & Min & 0.0461 & & -0.0081 & & & & -0.1826 & 0.0518 \\
\hline & Max & 0.3997 & & 0.0371 & & & & 0.9532 & 0.7831 \\
\hline & \#Sig. & 137 & & 9 & & & & 94 & 5 \\
\hline \multirow[t]{5}{*}{ (3) } & Mean & 0.1163 & & & 0.0295 & & & 0.3534 & 0.4205 \\
\hline & Median & 0.1079 & & & 0.0362 & & & 0.3399 & 0.4241 \\
\hline & Min & 0.0382 & & & -0.1172 & & & -0.1549 & 0.0512 \\
\hline & $\operatorname{Max}$ & 0.3590 & & & 0.1080 & & & 0.9108 & 0.8110 \\
\hline & \#Sig. & 143 & & & 46 & & & 107 & 5 \\
\hline \multirow[t]{5}{*}{ (4) } & Mean & 0.1212 & & & & 0.2989 & & 0.3564 & 0.4238 \\
\hline & Median & 0.1164 & & & & 0.0995 & & 0.3401 & 0.4162 \\
\hline & Min & 0.0522 & & & & -0.9867 & & -0.2355 & 0.0344 \\
\hline & $\operatorname{Max}$ & 0.3633 & & & & 1.8672 & & 0.9125 & 0.8029 \\
\hline & \#Sig. & 155 & & & & 55 & & 98 & 4 \\
\hline \multirow[t]{5}{*}{ (5) } & Mean & 0.1215 & & & & & 0.0268 & 0.3313 & 0.3962 \\
\hline & Median & 0.1153 & & & & & 0.0159 & 0.3281 & 0.3927 \\
\hline & Min & 0.0222 & & & & & -0.0352 & -0.2756 & 0.0487 \\
\hline & $\operatorname{Max}$ & 0.3680 & & & & & 0.1242 & 0.8121 & 0.7826 \\
\hline & \#Sig. & 139 & & & & & 18 & 96 & 4 \\
\hline \multirow[t]{5}{*}{ (6) } & Mean & 0.1100 & -1.5459 & 0.0045 & & & & 0.3706 & 0.4629 \\
\hline & Median & 0.1201 & -1.0263 & 0.0034 & & & & 0.3268 & 0.4474 \\
\hline & Min & -0.0170 & -5.1692 & -0.0167 & & & & 0.0711 & 0.0373 \\
\hline & Max & 0.2281 & 1.1095 & 0.0363 & & & & 0.9486 & 0.8846 \\
\hline & \#Sig. & 111 & 72 & 23 & & & & 110 & 19 \\
\hline \multirow[t]{5}{*}{ (7) } & Mean & 0.0900 & -1.4567 & & 0.0251 & & & 0.3909 & 0.4872 \\
\hline & Median & 0.0887 & -0.8152 & & 0.0336 & & & 0.4070 & 0.4896 \\
\hline & Min & 0.0062 & -5.2615 & & -0.1573 & & & 0.0863 & 0.0296 \\
\hline & Max & 0.1955 & 1.1865 & & 0.1170 & & & 0.9100 & 0.9016 \\
\hline & \#Sig. & 106 & 64 & & 49 & & & 123 & 23 \\
\hline \multirow[t]{5}{*}{$*(8)$} & Mean & 0.0952 & -2.3293 & & & -0.5306 & & 0.3745 & 0.5099 \\
\hline & Median & 0.0990 & -2.1415 & & & -0.4988 & & 0.3411 & 0.5016 \\
\hline & Min & 0.0102 & -7.1218 & & & -2.1573 & & 0.0237 & 0.1078 \\
\hline & $\operatorname{Max}$ & 0.1889 & 1.2984 & & & 0.7579 & & 0.9049 & 0.8935 \\
\hline & \#Sig. & 131 & 94 & & & 46 & & 128 & 15 \\
\hline \multirow[t]{5}{*}{ (9) } & Mean & 0.0929 & -1.5728 & & & & 0.0323 & 0.3690 & 0.4764 \\
\hline & Median & 0.1040 & -1.0701 & & & & 0.0223 & 0.3365 & 0.4830 \\
\hline & Min & -0.0054 & -4.6807 & & & & -0.0228 & -0.0201 & 0.0257 \\
\hline & Max & 0.1818 & 2.0994 & & & & 0.1427 & 0.8159 & 0.8874 \\
\hline & \#Sig. & 113 & 70 & & & & 25 & 119 & 13 \\
\hline
\end{tabular}


Table A.3. (Continued)

\begin{tabular}{|c|c|c|c|c|c|c|c|c|c|}
\hline & $\mathrm{RV}$ & MKT & CRED & VIX & SCLC & $10 y$ & MOM & $C$ & Rsq \\
\hline \multirow[t]{5}{*}{ (10) } & Mean & 0.1017 & -1.4813 & 0.0044 & 0.0246 & & & 0.3723 & 0.4846 \\
\hline & Median & 0.1087 & -0.8483 & 0.0041 & 0.0353 & & & 0.3527 & 0.4731 \\
\hline & Min & -0.0351 & -5.6298 & -0.0179 & -0.1638 & & & 0.0780 & -0.0073 \\
\hline & $\operatorname{Max}$ & 0.2237 & 1.1072 & 0.0384 & 0.1088 & & & 0.9423 & 0.9010 \\
\hline & \#Sig. & 98 & 64 & 24 & 49 & & & 113 & 25 \\
\hline \multirow[t]{5}{*}{$*(11)$} & Mean & 0.1048 & -2.2750 & 0.0028 & & -0.4828 & & 0.3516 & 0.5077 \\
\hline & Median & 0.1153 & -2.1504 & 0.0036 & & -0.5153 & & 0.3021 & 0.4859 \\
\hline & Min & -0.0095 & -6.7118 & -0.0219 & & -1.7058 & & 0.0122 & 0.0609 \\
\hline & Max & 0.2057 & 1.2949 & 0.0314 & & 0.7968 & & 0.9468 & 0.8937 \\
\hline & \#Sig. & 113 & 86 & 21 & & 41 & & 109 & 19 \\
\hline \multirow[t]{5}{*}{$(12)$} & Mean & 0.1078 & -1.5830 & 0.0050 & & & 0.0332 & 0.3520 & 0.4744 \\
\hline & Median & 0.1132 & -1.1352 & 0.0055 & & & 0.0255 & 0.3208 & 0.4795 \\
\hline & Min & -0.0194 & -4.9418 & -0.0125 & & & -0.0208 & 0.0470 & -0.0121 \\
\hline & Max & 0.2057 & 1.9277 & 0.0356 & & & 0.1377 & 0.8561 & 0.8819 \\
\hline & \#Sig. & 107 & 71 & 29 & & & 23 & 112 & 16 \\
\hline \multirow[t]{5}{*}{$*(13)$} & Mean & 0.0968 & -2.2018 & 0.0030 & 0.0279 & -0.4614 & & 0.3604 & 0.5316 \\
\hline & Median & 0.1064 & -1.9301 & 0.0038 & 0.0382 & -0.4829 & & 0.3370 & 0.5019 \\
\hline & Min & -0.0375 & -6.9707 & -0.0260 & -0.1466 & -2.1563 & & 0.0057 & 0.0164 \\
\hline & Max & 0.2004 & 1.3272 & 0.0349 & 0.1222 & 0.9637 & & 0.9438 & 0.9067 \\
\hline & \#Sig. & 98 & 83 & 20 & 49 & 47 & & 110 & 27 \\
\hline \multirow[t]{5}{*}{ (14) } & Mean & 0.1014 & -1.4341 & 0.0048 & 0.0264 & & 0.0282 & 0.3622 & 0.4964 \\
\hline & Median & 0.1100 & -0.8313 & 0.0051 & 0.0335 & & 0.0163 & 0.3293 & 0.4978 \\
\hline & Min & -0.0497 & -5.7070 & -0.0221 & -0.1664 & & -0.0332 & 0.0686 & -0.0631 \\
\hline & Max & 0.1991 & 1.9812 & 0.0390 & 0.1343 & & 0.1455 & 0.8695 & 0.8957 \\
\hline & \#Sig. & 98 & 69 & 26 & 50 & & 29 & 111 & 26 \\
\hline \multirow[t]{5}{*}{$*(15)$} & Mean & 0.1006 & -2.1809 & 0.0037 & 0.0284 & -0.5028 & 0.0276 & 0.3515 & 0.5417 \\
\hline & Median & 0.1061 & -2.1547 & 0.0054 & 0.0341 & -0.4396 & 0.0196 & 0.3298 & 0.5064 \\
\hline & Min & -0.0249 & -6.7947 & -0.0244 & -0.1367 & -1.9883 & -0.0292 & 0.0056 & 0.1141 \\
\hline & Max & 0.1798 & 1.7230 & 0.0344 & 0.1433 & 0.6013 & 0.1329 & 0.8710 & 0.9016 \\
\hline & \#Sig. & 102 & 88 & 21 & 40 & 48 & 16 & 107 & 26 \\
\hline
\end{tabular}

Notes: This table reports results from two-factor, three-factor, four-factor, five-factor, and six-factor rolling regression analyses using as dependent variable the monthly returns on RV portfolio. The sample period ranges from January 1994 to December 2008, and the rolling regression analyses are performed using the 24-month window. Risk factors in this table are selected from the rolling regression analyses of the single-factor model based on the number of time frame during which coefficients are significant at $5 \%$ significance level using the mean $R$-squared value. The results include mean, median, minimum, and maximum regression coefficients of each variable; number of time frames during which coefficients of each variable is significant at $5 \%$ significance level; and mean, median, minimum, and maximum adjusted $R$-squared value, as well as number of time frames during which adjusted $R$-squared value (\#Sig.) is greater than $70 \%$. Figures in bold and "*" indicate the best models in each level that show the most stable and highest $R$-squared value based on the mean adjusted $R$-squared value and \#Sig.

US Financial Crisis in 2008. In the figure for CUSUM, we can also observe that CUSUM starts declining sharply after 2000 and that it finally goes out of the lower bound in 2008. This may be sufficient partial evidence to say that regression coefficients are unstable over the time periods. 
Table A.4. Results from the multi-factor rolling regression analysis with 24-month window using selected risk factors.

\begin{tabular}{|c|c|c|c|c|c|c|c|c|c|}
\hline & SS & MKT & VIX & SCLC & $\mathrm{MOM}$ & HML & CRED & $C$ & Rsq \\
\hline \multirow[t]{5}{*}{ (1) } & Mean & 0.5854 & 0.0160 & & & & & 0.4825 & 0.7397 \\
\hline & Median & 0.6067 & 0.0145 & & & & & 0.3833 & 0.7362 \\
\hline & Min & 0.3413 & -0.0283 & & & & & -0.0898 & 0.5223 \\
\hline & Max & 0.8056 & 0.0883 & & & & & 1.8449 & 0.8945 \\
\hline & \#Sig. & 157 & 26 & & & & & 81 & 106 \\
\hline \multirow[t]{5}{*}{$*(2)$} & Mean & 0.4877 & & 0.2239 & & & & 0.5850 & 0.8323 \\
\hline & Median & 0.5018 & & 0.2398 & & & & 0.4249 & 0.8525 \\
\hline & Min & 0.3030 & & -0.2244 & & & & -0.0582 & 0.5359 \\
\hline & $\operatorname{Max}$ & 0.6733 & & 0.4177 & & & & 1.6121 & 0.9527 \\
\hline & \#Sig. & 157 & & 141 & & & & 119 & 142 \\
\hline \multirow[t]{5}{*}{ (3) } & Mean & 0.5289 & & & 0.0651 & & & 0.4792 & 0.7713 \\
\hline & Median & 0.5444 & & & 0.0583 & & & 0.4170 & 0.7840 \\
\hline & Min & 0.3113 & & & -0.2034 & & & -0.1249 & 0.5648 \\
\hline & Max & 0.7512 & & & 0.3444 & & & 1.6340 & 0.8807 \\
\hline & \#Sig. & 157 & & & 72 & & & 82 & 138 \\
\hline \multirow[t]{5}{*}{ (4) } & Mean & 0.5380 & & & & 0.0183 & & 0.4897 & 0.7478 \\
\hline & Median & 0.5372 & & & & 0.0192 & & 0.3896 & 0.7580 \\
\hline & Min & 0.3881 & & & & -0.3043 & & -0.0720 & 0.4984 \\
\hline & Max & 0.7239 & & & & 0.2903 & & 1.8069 & 0.8857 \\
\hline & \#Sig. & 157 & & & & 46 & & 73 & 114 \\
\hline \multirow[t]{5}{*}{ (5) } & Mean & 0.5310 & & & & & -2.9243 & 0.5172 & 0.7518 \\
\hline & Median & 0.5636 & & & & & -2.2382 & 0.3707 & 0.7632 \\
\hline & Min & 0.2279 & & & & & -13.5164 & 0.0647 & 0.5014 \\
\hline & Max & 0.8094 & & & & & 2.1844 & 1.8730 & 0.8792 \\
\hline & \#Sig. & 157 & & & & & 41 & 76 & 122 \\
\hline \multirow[t]{5}{*}{$*(6)$} & Mean & 0.5330 & 0.0177 & 0.2260 & & & & 0.5470 & 0.8394 \\
\hline & Median & 0.5391 & 0.0100 & 0.2391 & & & & 0.4128 & 0.8667 \\
\hline & Min & 0.2759 & -0.0252 & -0.2259 & & & & -0.0946 & 0.5449 \\
\hline & Max & 0.8288 & 0.0931 & 0.3919 & & & & 1.6555 & 0.9565 \\
\hline & \#Sig. & 157 & 49 & 138 & & & & 107 & 141 \\
\hline \multirow[t]{5}{*}{ (7) } & Mean & 0.5851 & 0.0190 & & 0.0691 & & & 0.4394 & 0.7772 \\
\hline & Median & 0.6009 & 0.0178 & & 0.0578 & & & 0.3924 & 0.7830 \\
\hline & Min & 0.2821 & -0.0264 & & -0.2048 & & & -0.1891 & 0.5447 \\
\hline & Max & 0.7857 & 0.0849 & & 0.3591 & & & 1.6869 & 0.9017 \\
\hline & \#Sig. & 157 & 36 & & 73 & & & 71 & 139 \\
\hline \multirow[t]{5}{*}{ (8) } & Mean & 0.5818 & 0.0169 & & & 0.0187 & & 0.4625 & 0.7515 \\
\hline & Median & 0.5962 & 0.0120 & & & 0.0190 & & 0.3718 & 0.7530 \\
\hline & Min & 0.3634 & -0.0298 & & & -0.3161 & & -0.1197 & 0.5019 \\
\hline & $\operatorname{Max}$ & 0.8247 & 0.0885 & & & 0.2916 & & 1.8944 & 0.8905 \\
\hline & \#Sig. & 157 & 25 & & & 45 & & 65 & 112 \\
\hline \multirow[t]{5}{*}{ (9) } & Mean & 0.5740 & 0.0153 & & & & -2.8988 & 0.4781 & 0.7554 \\
\hline & Median & 0.6301 & 0.0148 & & & & -2.2403 & 0.3452 & 0.7555 \\
\hline & Min & 0.1983 & -0.0277 & & & & -13.5325 & -0.0720 & 0.5048 \\
\hline & Max & 0.7972 & 0.0808 & & & & 2.2359 & 1.8967 & 0.9002 \\
\hline & \#Sig. & 157 & 22 & & & & 45 & 67 & 124 \\
\hline
\end{tabular}


Table A.4. (Continued)

\begin{tabular}{|c|c|c|c|c|c|c|c|c|c|}
\hline & SS & MKT & VIX & SCLC & MOM & HML & CRED & $C$ & Rsq \\
\hline \multirow[t]{5}{*}{$*(10)$} & Mean & 0.5448 & 0.0196 & 0.2065 & 0.0750 & & & 0.5025 & 0.8588 \\
\hline & Median & 0.5591 & 0.0162 & 0.2295 & 0.0310 & & & 0.3886 & 0.8629 \\
\hline & Min & 0.2409 & -0.0250 & -0.1259 & -0.0407 & & & -0.1722 & 0.6676 \\
\hline & Max & 0.8168 & 0.0897 & 0.3980 & 0.3306 & & & 1.6355 & 0.9542 \\
\hline & \#Sig. & 157 & 51 & 119 & 44 & & & 100 & 154 \\
\hline \multirow[t]{5}{*}{ (11) } & Mean & 0.5426 & 0.0186 & 0.2286 & & 0.0478 & & 0.4974 & 0.8456 \\
\hline & Median & 0.5417 & 0.0134 & 0.2389 & & 0.0350 & & 0.3251 & 0.8650 \\
\hline & Min & 0.2851 & -0.0269 & -0.0799 & & -0.2856 & & -0.0868 & 0.5261 \\
\hline & Max & 0.8359 & 0.0952 & 0.4235 & & 0.2622 & & 1.6930 & 0.9567 \\
\hline & \#Sig. & 157 & 48 & 133 & & 46 & & 84 & 141 \\
\hline \multirow[t]{5}{*}{$(12)$} & Mean & 0.5213 & 0.0176 & 0.2186 & & & -1.4839 & 0.5506 & 0.8452 \\
\hline & Median & 0.5485 & 0.0127 & 0.2352 & & & -1.4591 & 0.4175 & 0.8680 \\
\hline & Min & 0.2027 & -0.0257 & -0.3134 & & & -6.9734 & -0.0769 & 0.5273 \\
\hline & Max & 0.8235 & 0.0969 & 0.3771 & & & 3.9028 & 1.6532 & 0.9587 \\
\hline & \#Sig. & 156 & 51 & 140 & & & 39 & 113 & 143 \\
\hline \multirow[t]{5}{*}{ (13) } & Mean & 0.5437 & 0.0199 & 0.2104 & 0.0632 & 0.0490 & & 0.4737 & 0.8608 \\
\hline & Median & 0.5599 & 0.0158 & 0.2269 & 0.0245 & 0.0435 & & 0.3271 & 0.8622 \\
\hline & Min & 0.2492 & -0.0267 & -0.0919 & -0.0547 & -0.2591 & & -0.1836 & 0.6534 \\
\hline & Max & 0.8218 & 0.0918 & 0.4268 & 0.3136 & 0.2833 & & 1.6743 & 0.9543 \\
\hline & \#Sig. & 157 & 52 & 120 & 36 & 31 & & 81 & 154 \\
\hline \multirow[t]{5}{*}{$*(14)$} & Mean & 0.5314 & 0.0196 & 0.1996 & 0.0732 & & -1.6080 & 0.5123 & 0.8648 \\
\hline & Median & 0.5289 & 0.0171 & 0.2232 & 0.0289 & & -1.7341 & 0.3838 & 0.8643 \\
\hline & Min & 0.2309 & -0.0257 & -0.2129 & -0.0497 & & -7.4954 & -0.0764 & 0.7095 \\
\hline & Max & 0.8163 & 0.0909 & 0.3773 & 0.3965 & & 3.7343 & 1.6437 & 0.9587 \\
\hline & \#Sig. & 157 & 50 & 122 & 39 & & 47 & 103 & 157 \\
\hline \multirow[t]{5}{*}{$*(15)$} & Mean & 0.5352 & 0.0211 & 0.2069 & 0.0627 & 0.0463 & -1.8173 & 0.4788 & 0.8685 \\
\hline & Median & 0.5275 & 0.0172 & 0.2208 & 0.0200 & 0.0348 & -2.1035 & 0.3215 & 0.8734 \\
\hline & Min & 0.2368 & -0.0269 & -0.1743 & -0.0639 & -0.2634 & -9.7522 & -0.0527 & 0.6924 \\
\hline & Max & 0.8426 & 0.0996 & 0.4280 & 0.4024 & 0.2388 & 3.1757 & 1.6847 & 0.9587 \\
\hline & \#Sig. & 157 & 61 & 123 & 32 & 37 & 43 & 73 & 155 \\
\hline
\end{tabular}

Notes: This table reports results from two-factor, three-factor, four-factor, five-factor, and six-factor rolling regression analyses using as dependent variable the monthly returns on SS portfolio. The sample period ranges from January 1994 to December 2008, and the rolling regression analyses are performed using the 24-month window. Risk factors in this table are selected from the rolling regression analyses of the single-factor model based on the number of time frame during which coefficients are significant at $5 \%$ significance level using the mean $R$-squared value. The results include mean, median, minimum, and maximum regression coefficients of each variable; number of time frames during which coefficients of each variable is significant at $5 \%$ significance level; and mean, median, minimum, and maximum adjusted $R$-squared value, as well as number of time frames during which adjusted $R$-squared value (\#Sig.) is greater than $70 \%$. Figures in bold and "*" indicate the best models in each level that show the most stable and highest $R$-squared value based on the mean adjusted $R$-squared value and \# Sig.

Specifically, figures for the DT portfolio are very similar to those of the aggregate hedge fund portfolio in terms of the movements of the recursive residuals, CUSUM and CUSUM of squares. However, the rest of the figures displays different movements. Recursive residuals in the RV portfolio maintain relatively narrow $95 \%$ 
Table A.5. Results from the multi-factor rolling regression analysis with 24-month window using selected risk factors.

\begin{tabular}{|c|c|c|c|c|c|c|c|c|c|}
\hline & MP & MKT & SCLC & VIX & CRED & HML & MOM & C & Rsq \\
\hline \multirow[t]{5}{*}{$*(1)$} & Mean & 0.2476 & 0.0971 & & & & & 0.5458 & 0.6265 \\
\hline & Median & 0.2694 & 0.1191 & & & & & 0.5048 & 0.6458 \\
\hline & Min & 0.0619 & -0.1755 & & & & & -0.2047 & 0.1443 \\
\hline & $\operatorname{Max}$ & 0.3858 & 0.2614 & & & & & 1.1744 & 0.8975 \\
\hline & \#Sig. & 154 & 94 & & & & & 134 & 57 \\
\hline \multirow{5}{*}{ (2) } & Mean & 0.3039 & & 0.0118 & & & & 0.4870 & 0.5611 \\
\hline & Median & 0.3262 & & 0.0123 & & & & 0.4468 & 0.5803 \\
\hline & Min & 0.0729 & & -0.0207 & & & & -0.2439 & 0.1026 \\
\hline & $\operatorname{Max}$ & 0.4591 & & 0.0633 & & & & 1.3151 & 0.8403 \\
\hline & \#Sig. & 152 & & 24 & & & & 115 & 20 \\
\hline \multirow[t]{5}{*}{ (3) } & Mean & 0.2464 & & & -2.4677 & & & 0.5430 & 0.6062 \\
\hline & Median & 0.2790 & & & -2.9058 & & & 0.4776 & 0.6246 \\
\hline & Min & 0.0095 & & & -6.5783 & & & -0.1497 & 0.0807 \\
\hline & $\operatorname{Max}$ & 0.3812 & & & 2.9567 & & & 1.3227 & 0.8941 \\
\hline & \#Sig. & 148 & & & 84 & & & 143 & 48 \\
\hline \multirow[t]{5}{*}{ (4) } & Mean & 0.2776 & & & & 0.0619 & & 0.4789 & 0.5866 \\
\hline & Median & 0.2858 & & & & 0.0650 & & 0.4744 & 0.6042 \\
\hline & Min & 0.1259 & & & & -0.2090 & & -0.3162 & 0.2888 \\
\hline & Max & 0.4215 & & & & 0.2460 & & 1.2523 & 0.8352 \\
\hline & \#Sig. & 157 & & & & 48 & & 104 & 34 \\
\hline \multirow[t]{5}{*}{ (5) } & Mean & 0.2635 & & & & & 0.0141 & 0.5038 & 0.5654 \\
\hline & Median & 0.2782 & & & & & 0.0111 & 0.4759 & 0.5978 \\
\hline & Min & 0.0703 & & & & & -0.1269 & -0.3751 & 0.0753 \\
\hline & $\operatorname{Max}$ & 0.3804 & & & & & 0.1444 & 1.1989 & 0.8628 \\
\hline & \#Sig. & 154 & & & & & 35 & 119 & 27 \\
\hline \multirow[t]{5}{*}{ (6) } & Mean & 0.2820 & 0.1017 & 0.0123 & & & & 0.5138 & 0.6374 \\
\hline & Median & 0.2984 & 0.1176 & 0.0121 & & & & 0.4679 & 0.6487 \\
\hline & Min & 0.0338 & -0.1764 & -0.0254 & & & & -0.2092 & 0.1441 \\
\hline & $\operatorname{Max}$ & 0.4698 & 0.2547 & 0.0641 & & & & 1.2043 & 0.8962 \\
\hline & \#Sig. & 145 & 93 & 36 & & & & 118 & 59 \\
\hline \multirow[t]{5}{*}{$*(7)$} & Mean & 0.2270 & 0.0906 & & -1.8715 & & & 0.5723 & 0.6660 \\
\hline & Median & 0.2554 & 0.1031 & & -1.8262 & & & 0.5458 & 0.6817 \\
\hline & Min & 0.0202 & -0.2320 & & -5.6762 & & & -0.0358 & 0.1071 \\
\hline & Max & 0.3860 & 0.2691 & & 3.1410 & & & 1.1781 & 0.9192 \\
\hline & \#Sig. & 143 & 100 & & 76 & & & 145 & 72 \\
\hline \multirow[t]{5}{*}{ (8) } & Mean & 0.2637 & 0.0938 & & & 0.0742 & & 0.4960 & 0.6531 \\
\hline & Median & 0.2827 & 0.1182 & & & 0.0485 & & 0.4792 & 0.6717 \\
\hline & Min & 0.0979 & -0.1502 & & & -0.1503 & & -0.2559 & 0.2658 \\
\hline & $\operatorname{Max}$ & 0.4048 & 0.2697 & & & 0.2481 & & 1.1277 & 0.8962 \\
\hline & \#Sig. & 157 & 92 & & & 46 & & 114 & 61 \\
\hline \multirow[t]{5}{*}{ (9) } & Mean & 0.2479 & 0.0909 & & & & 0.0158 & 0.5338 & 0.6207 \\
\hline & Median & 0.2719 & 0.1081 & & & & 0.0113 & 0.5350 & 0.6451 \\
\hline & Min & 0.0525 & -0.1318 & & & & -0.0590 & -0.3175 & 0.1040 \\
\hline & Max & 0.3923 & 0.2661 & & & & 0.1270 & 1.1586 & 0.8959 \\
\hline & \#Sig. & 150 & 90 & & & & 12 & 133 & 63 \\
\hline
\end{tabular}


Table A.5. (Continued)

\begin{tabular}{|c|c|c|c|c|c|c|c|c|c|}
\hline & MP & MKT & SCLC & VIX & CRED & HML & MOM & $C$ & Rsq \\
\hline \multirow[t]{5}{*}{$*(10)$} & Mean & 0.2613 & 0.0950 & 0.0123 & -1.8627 & & & 0.5342 & 0.6784 \\
\hline & Median & 0.2797 & 0.0999 & 0.0116 & -2.0149 & & & 0.4746 & 0.6933 \\
\hline & Min & -0.0450 & -0.2631 & -0.0258 & -5.9446 & & & -0.0241 & 0.1127 \\
\hline & Max & 0.4690 & 0.2682 & 0.0653 & 3.1607 & & & 1.1889 & 0.9272 \\
\hline & \#Sig. & 137 & 99 & 41 & 71 & & & 128 & 74 \\
\hline \multirow[t]{5}{*}{ (11) } & Mean & 0.2988 & 0.1001 & 0.0130 & & 0.0779 & & 0.4660 & 0.6667 \\
\hline & Median & 0.3220 & 0.1178 & 0.0126 & & 0.0613 & & 0.4428 & 0.6767 \\
\hline & Min & 0.0432 & -0.0997 & -0.0278 & & -0.1545 & & -0.2633 & 0.2485 \\
\hline & Max & 0.5042 & 0.2659 & 0.0639 & & 0.2605 & & 1.1845 & 0.8949 \\
\hline & \#Sig. & 139 & 92 & 35 & & 46 & & 93 & 64 \\
\hline \multirow[t]{5}{*}{ (12) } & Mean & 0.2857 & 0.0930 & 0.0125 & & & 0.0193 & 0.4995 & 0.6341 \\
\hline & Median & 0.3096 & 0.1062 & 0.0134 & & & 0.0127 & 0.4726 & 0.6645 \\
\hline & Min & 0.0013 & -0.1253 & -0.0254 & & & -0.0663 & -0.3338 & 0.0998 \\
\hline & Max & 0.4735 & 0.2592 & 0.0629 & & & 0.1435 & 1.1986 & 0.8946 \\
\hline & \#Sig. & 140 & 83 & 40 & & & 15 & 117 & 64 \\
\hline \multirow[t]{5}{*}{$*(13)$} & Mean & 0.2804 & 0.0947 & 0.0138 & -1.9683 & 0.0697 & & 0.4907 & 0.7069 \\
\hline & Median & 0.3007 & 0.0995 & 0.0133 & -2.0492 & 0.0733 & & 0.4488 & 0.7267 \\
\hline & Min & -0.0264 & -0.1966 & -0.0292 & -6.5212 & -0.1344 & & -0.0696 & 0.2227 \\
\hline & Max & 0.5360 & 0.2635 & 0.0630 & 2.9746 & 0.2313 & & 1.1913 & 0.9237 \\
\hline & \#Sig. & 136 & 100 & 45 & 71 & 52 & & 104 & 83 \\
\hline \multirow[t]{5}{*}{ (14) } & Mean & 0.2650 & 0.0862 & 0.0128 & -1.9735 & & 0.0205 & 0.5245 & 0.6786 \\
\hline & Median & 0.2879 & 0.0938 & 0.0151 & -2.0089 & & 0.0146 & 0.4955 & 0.7029 \\
\hline & Min & -0.0107 & -0.2441 & -0.0265 & -5.9395 & & -0.0630 & -0.1424 & 0.0691 \\
\hline & Max & 0.4730 & 0.2591 & 0.0642 & 2.6357 & & 0.1893 & 1.1881 & 0.9279 \\
\hline & \#Sig. & 135 & 83 & 42 & 71 & & 20 & 129 & 80 \\
\hline \multirow[t]{5}{*}{$*(15)$} & Mean & 0.2760 & 0.0905 & 0.0132 & -2.0545 & 0.0752 & 0.0098 & 0.4808 & 0.7063 \\
\hline & Median & 0.3001 & 0.0941 & 0.0138 & -1.8638 & 0.0751 & -0.0013 & 0.4575 & 0.7244 \\
\hline & Min & -0.0075 & -0.1976 & -0.0290 & -6.9683 & -0.1370 & -0.0718 & -0.1486 & 0.1775 \\
\hline & Max & 0.5224 & 0.2511 & 0.0603 & 2.3480 & 0.3440 & 0.1729 & 1.1888 & 0.9244 \\
\hline & \#Sig. & 127 & 88 & 49 & 72 & 45 & 11 & 103 & 85 \\
\hline
\end{tabular}

Notes: This table reports results from two-factor, three-factor, four-factor, five-factor, and six-factor rolling regression analyses using as dependent variable the monthly returns on MP portfolio. The sample period ranges from January 1994 to December 2008, and the rolling regression analyses are performed using the 24-month window. Risk factors in this table are selected from the rolling regression analyses of the single-factor model based on the number of time frame during which coefficients are significant at $5 \%$ significance level using mean $R$-squared value. The results include mean, median, minimum, and maximum regression coefficients of each variable; number of time frames during which coefficients of each variable is significant at $5 \%$ significance level; and mean, median, minimum, and maximum adjusted $R$-squared value, as well as number of time frames during which adjusted $R$-squared value (\#Sig.) is greater than $70 \%$. Figures in bold and "*" indicate the best models in each level that show the most stable and highest $R$-squared value based on the mean adjusted $R$-squared value and \#Sig.

critical bounds and show greater out of bound jumps around 1998 and 2008. CUSUM of squares stays out of bound all the way from 1997 to 2008. This indicates that regression coefficients for the RV portfolio are unstable over the majority of the sample periods. Figures for the SS portfolio commonly exhibit violations of bounds 
Table A.6. Results from the multi-factor rolling regression analysis with 24-month window using selected risk factors.

\begin{tabular}{|c|c|c|c|c|c|c|c|c|c|}
\hline & FoF & EMF & VIX & SCLC & CRED & MOM & HML & $C$ & Rsq \\
\hline \multirow[t]{5}{*}{ (1) } & Mean & 0.1836 & 0.0056 & & & & & 0.3540 & 0.5983 \\
\hline & Median & 0.1848 & 0.0069 & & & & & 0.2683 & 0.5880 \\
\hline & Min & 0.0679 & -0.0246 & & & & & -0.4463 & 0.3195 \\
\hline & Max & 0.2922 & 0.0501 & & & & & 1.1234 & 0.8692 \\
\hline & \#Sig. & 157 & 25 & & & & & 81 & 29 \\
\hline \multirow[t]{5}{*}{ (2) } & Mean & 0.1652 & & 0.0602 & & & & 0.3764 & 0.6242 \\
\hline & Median & 0.1714 & & 0.0696 & & & & 0.2612 & 0.6172 \\
\hline & Min & 0.0675 & & -0.2044 & & & & -0.4730 & 0.3140 \\
\hline & Max & 0.2640 & & 0.2016 & & & & 1.2267 & 0.8566 \\
\hline & \#Sig. & 157 & & 52 & & & & 85 & 42 \\
\hline \multirow[t]{5}{*}{ (3) } & Mean & 0.1675 & & & -0.9888 & & & 0.3945 & 0.6112 \\
\hline & Median & 0.1657 & & & -1.2752 & & & 0.2668 & 0.5990 \\
\hline & Min & 0.0637 & & & -5.2728 & & & -0.2767 & 0.3279 \\
\hline & Max & 0.2723 & & & 3.9899 & & & 1.0993 & 0.8591 \\
\hline & \#Sig. & 157 & & & 45 & & & 83 & 35 \\
\hline \multirow[t]{5}{*}{$*(4)$} & Mean & 0.1784 & & & & 0.0410 & & 0.3058 & 0.6386 \\
\hline & Median & 0.1819 & & & & 0.0278 & & 0.2459 & 0.6287 \\
\hline & Min & 0.0951 & & & & -0.0773 & & -0.7178 & 0.3170 \\
\hline & Max & 0.2705 & & & & 0.1926 & & 1.0933 & 0.8736 \\
\hline & \#Sig. & 157 & & & & 43 & & 68 & 58 \\
\hline \multirow[t]{5}{*}{ (5) } & Mean & 0.1755 & & & & & 0.0245 & 0.3453 & 0.6017 \\
\hline & Median & 0.1717 & & & & & 0.0329 & 0.2531 & 0.5897 \\
\hline & Min & 0.0787 & & & & & -0.1884 & -0.5797 & 0.2649 \\
\hline & Max & 0.2670 & & & & & 0.1838 & 1.1376 & 0.8582 \\
\hline & \#Sig. & 157 & & & & & 24 & 76 & 35 \\
\hline \multirow[t]{5}{*}{ (6) } & Mean & 0.1727 & 0.0050 & 0.0646 & & & & 0.3680 & 0.6284 \\
\hline & Median & 0.1747 & 0.0068 & 0.0741 & & & & 0.2583 & 0.6122 \\
\hline & Min & 0.0272 & -0.0245 & -0.1909 & & & & -0.4636 & 0.2927 \\
\hline & Max & 0.2910 & 0.0468 & 0.2016 & & & & 1.2278 & 0.8754 \\
\hline & \#Sig. & 155 & 28 & 49 & & & & 85 & 41 \\
\hline \multirow[t]{5}{*}{ (7) } & Mean & 0.1788 & 0.0065 & & -1.0648 & & & 0.3846 & 0.6181 \\
\hline & Median & 0.1718 & 0.0092 & & -1.1561 & & & 0.2608 & 0.6066 \\
\hline & Min & 0.0652 & -0.0242 & & -5.5255 & & & -0.2901 & 0.3232 \\
\hline & Max & 0.2951 & 0.0485 & & 3.9192 & & & 1.1247 & 0.8684 \\
\hline & \#Sig. & 157 & 34 & & 42 & & & 80 & 40 \\
\hline \multirow[t]{5}{*}{$*(8)$} & Mean & 0.1886 & 0.0061 & & & 0.0407 & & 0.2983 & 0.6441 \\
\hline & Median & 0.1838 & 0.0064 & & & 0.0247 & & 0.2380 & 0.6431 \\
\hline & Min & 0.0961 & -0.0248 & & & -0.0748 & & -0.6354 & 0.2937 \\
\hline & Max & 0.2940 & 0.0557 & & & 0.1974 & & 1.1170 & 0.8755 \\
\hline & \#Sig. & 157 & 33 & & & 41 & & 70 & 59 \\
\hline \multirow[t]{5}{*}{ (9) } & Mean & 0.1844 & 0.0055 & & & & 0.0226 & 0.3398 & 0.6032 \\
\hline & Median & 0.1799 & 0.0061 & & & & 0.0218 & 0.2517 & 0.5892 \\
\hline & Min & 0.0588 & -0.0237 & & & & -0.1964 & -0.5098 & 0.2997 \\
\hline & Max & 0.3308 & 0.0501 & & & & 0.2086 & 1.1586 & 0.8653 \\
\hline & \#Sig. & 157 & 20 & & & & 20 & 78 & 32 \\
\hline
\end{tabular}


Table A.6. (Continued)

\begin{tabular}{|c|c|c|c|c|c|c|c|c|c|}
\hline & FoF & $\mathrm{EMF}$ & VIX & SCLC & CRED & MOM & HML & $C$ & Rsq \\
\hline \multirow[t]{5}{*}{ (10) } & Mean & 0.1696 & 0.0066 & 0.0626 & -0.7193 & & & 0.4034 & 0.6570 \\
\hline & Median & 0.1641 & 0.0080 & 0.0709 & -1.0509 & & & 0.2559 & 0.6674 \\
\hline & Min & 0.0420 & -0.0248 & -0.3336 & -5.5528 & & & -0.3084 & 0.3139 \\
\hline & Max & 0.3013 & 0.0550 & 0.2327 & 5.2599 & & & 1.2301 & 0.8777 \\
\hline & \#Sig. & 154 & 40 & 65 & 56 & & & 80 & 59 \\
\hline \multirow[t]{5}{*}{$*(11)$} & Mean & 0.1783 & 0.0055 & 0.0628 & & 0.0458 & & 0.3244 & 0.6579 \\
\hline & Median & 0.1790 & 0.0065 & 0.0563 & & 0.0284 & & 0.2609 & 0.6580 \\
\hline & Min & 0.0590 & -0.0233 & -0.1196 & & -0.0713 & & -0.5724 & 0.2616 \\
\hline & Max & 0.2941 & 0.0536 & 0.2308 & & 0.2134 & & 1.1830 & 0.8751 \\
\hline & \#Sig. & 157 & 34 & 38 & & 47 & & 77 & 67 \\
\hline \multirow[t]{5}{*}{$(12)$} & Mean & 0.1729 & 0.0051 & 0.0673 & & & 0.0309 & 0.3580 & 0.6320 \\
\hline & Median & 0.1699 & 0.0069 & 0.0681 & & & 0.0288 & 0.2504 & 0.6269 \\
\hline & Min & 0.0124 & -0.0233 & -0.2012 & & & -0.1587 & -0.5252 & 0.3151 \\
\hline & Max & 0.3293 & 0.0467 & 0.2386 & & & 0.2076 & 1.2320 & 0.8730 \\
\hline & \#Sig. & 152 & 24 & 52 & & & 19 & 81 & 50 \\
\hline \multirow[t]{5}{*}{$*(13)$} & Mean & 0.1692 & 0.0068 & 0.0609 & -0.9452 & 0.0517 & & 0.3661 & 0.6845 \\
\hline & Median & 0.1674 & 0.0090 & 0.0566 & -1.1636 & 0.0526 & & 0.2555 & 0.7142 \\
\hline & Min & 0.0619 & -0.0237 & -0.2663 & -6.3679 & -0.0837 & & -0.2929 & 0.2852 \\
\hline & Max & 0.2731 & 0.0694 & 0.2502 & 5.2699 & 0.2256 & & 1.1852 & 0.8732 \\
\hline & \#Sig. & 157 & 42 & 52 & 55 & 47 & & 75 & 84 \\
\hline \multirow[t]{5}{*}{ (14) } & Mean & 0.1670 & 0.0079 & 0.0669 & -0.7791 & & 0.0168 & 0.3997 & 0.6626 \\
\hline & Median & 0.1611 & 0.0078 & 0.0739 & -0.9747 & & 0.0178 & 0.2320 & 0.6726 \\
\hline & Min & 0.0257 & -0.0243 & -0.2815 & -5.5069 & & -0.1568 & -0.3967 & 0.3368 \\
\hline & Max & 0.2945 & 0.0688 & 0.2588 & 5.1267 & & 0.2062 & 1.2330 & 0.8711 \\
\hline & \#Sig. & 155 & 38 & 59 & 58 & & 22 & 77 & 67 \\
\hline \multirow[t]{5}{*}{$*(15)$} & Mean & 0.1681 & 0.0064 & 0.0635 & -1.0944 & 0.0518 & 0.0490 & 0.3537 & 0.6913 \\
\hline & Median & 0.1638 & 0.0085 & 0.0624 & -1.1048 & 0.0565 & 0.0380 & 0.2283 & 0.7133 \\
\hline & Min & 0.0493 & -0.0244 & -0.2489 & -6.0409 & -0.0795 & -0.0968 & -0.3852 & 0.3455 \\
\hline & $\operatorname{Max}$ & 0.2831 & 0.0688 & 0.2532 & 5.1555 & 0.2207 & 0.2917 & 1.1880 & 0.8658 \\
\hline & \#Sig. & 153 & 35 & 44 & 49 & 45 & 19 & 72 & 83 \\
\hline
\end{tabular}

Notes: This table reports results from two-factor, three-factor, four-factor, five-factor, and six-factor rolling regression analyses using as dependent variable the monthly returns on FoF portfolio. The sample period ranges from January 1994 to December 2008, and the rolling regression analyses are performed using the 24-month window. Risk factors in this table are selected from the rolling regression analyses of the single-factor model based on the number of time frame during which coefficients are significant at $5 \%$ significance level using mean $R$-squared value. The results include mean, median, minimum, and maximum regression coefficients of each variable; number of time frames during which coefficients of each variable is significant at $5 \%$ significance level; and mean, median, minimum, and maximum adjusted $R$-squared value, as well as number of time frames during which adjusted $R$-squared value (\#Sig.) is greater than $70 \%$. Figures in bold and "*" indicate the best models in each level that show the most stable and highest $R$-squared value based on the mean adjusted $R$-squared value and \# Sig.

around periods of the Dot.com bubble burst between 2000 and 2003. It shows that during that period, the SS portfolio has substantially changed its exposure to equity market-related risk factors. In the figures of the MP and FoF portfolios, we can observe bound violations during critical financial events that substantially affected 
the global economy. All these figures commonly indicate that hedge fund portfolios with different strategies respond more actively and change their risk exposure to events, which affect global economies severely. Since the world economy is more global than in the past, these events will occur more frequently in the future. Thus, the tendency is that hedge funds actively respond to such events more frequently, and so does the instability of regression coefficients.

With the results of the two methods examining the stability of regression coefficients from single index model, we conclude that the coefficients are unstable, especially when an event affects the global economy. In addition, with a recent pattern of globalization, highly developed investment techniques and active hedge fund management of exposure to risk factors, the stability of the regression coefficients from the model is more likely to deteriorate in the future. Therefore, the rolling regression model is more efficient in capturing the dynamic management style of hedge funds and in measuring hedge fund exposure to a variety of risk factors.

\section{References}

V. Agarwal, N. D. Daniel \& N. Y. Naik (2009) Role of managerial incentives and discretion in hedge fund performance, Journal of Finance 64, 2221-2256.

R. K. Aggarwal \& P. Jorion (2009) The risk of emerging hedge fund managers, Journal of Investing 18, 100-107.

A. Aiken, C. Clifford \& J. Ellis (2015) Hedge funds and discretionary liquidity restrictions, Journal of Financial Economics 116, 197-218.

T. Bali, S. Brown \& M. Caglayan (2014) Macroeconomic risk and hedge fund returns, Journal of Financial Economics 114, 1-19.

M. C. Jensen, F. Black \& M. Scholes (1972) The capital asset pricing model: Some empirical test. In Studies in the Theory of Capital Markets (M. C. Jensen, ed.), New York: Praeger Publisher Inc.

M. Busiere, M. Hoerova \& B. Klaus (2015) Commonality in hedge fund returns: Driving factors and implications, Journal of Banking and Finance 54, 266-280.

M. M. Carhart (1997) On persistence in mutual fund performance, Journal of Finance 52, $57-82$.

W. F. M. DeBondt \& R. Thaler (1985) Does the stock market overreact? Journal of Finance 40, 793-805.

E. F. Fama \& K. R. French (1993) Common risk factors in the returns on stocks and bonds, Journal of Financial Economics 33, 3-56.

W. Fung \& D. A. Hsieh (1997a) Empirical characteristics of dynamic trading strategies: The case of hedge funds, The Review of Financial Studies 10, 275-302.

W. Fung \& D. A. Hsieh (2004a) Hedge fund benchmarks: A risk-based approach, Financial Analysts Journal 60(5), 65-80.

W. Fung \& D. A. Hsieh (2004b) Extracting portable alphas from equity long/short hedge funds, Journal of Investment Management 2, 1-19.

M. C. Jensen (1967) The performance of mutual funds in the period of 1945-1964, Journal of Finance 23, 389-416.

Y. Qin \& M. Bai (2014) Foreign ownership restrictions and momentum - Evidence from emerging markets, International Finance Review 14, 237-261. 
R. C. Scott \& P. A. Horvath (1980) On the direction of preference for moments of higher order than the variance, Journal of Finance 35, 915-919.

W. Sharpe (1992) Asset allocation: Management style and performance measurement, Journal of Portfolio Management 18, 7-19. 